\title{
Origin and diversification of living cycads: a cautionary tale on the impact of the branching process prior in Bayesian molecular dating
}

Fabien L Condamine ${ }^{1,2^{*}}$, Nathalie S Nagalingum ${ }^{3}$, Charles R Marshall ${ }^{4}$ and Hélène Morlon ${ }^{5}$

\begin{abstract}
Background: Bayesian relaxed-clock dating has significantly influenced our understanding of the timeline of biotic evolution. This approach requires the use of priors on the branching process, yet little is known about their impact on divergence time estimates. We investigated the effect of branching priors using the iconic cycads. We conducted phylogenetic estimations for 237 cycad species using three genes and two calibration strategies incorporating up to six fossil constraints to (i) test the impact of two different branching process priors on age estimates, (ii) assess which branching prior better fits the data, (iii) investigate branching prior impacts on diversification analyses, and (iv) provide insights into the diversification history of cycads.

Results: Using Bayes factors, we compared divergence time estimates and the inferred dynamics of diversification when using Yule versus birth-death priors. Bayes factors were calculated with marginal likelihood estimated with stepping-stone sampling. We found striking differences in age estimates and diversification dynamics depending on prior choice. Dating with the Yule prior suggested that extant cycad genera diversified in the Paleogene and with two diversification rate shifts. In contrast, dating with the birth-death prior yielded Neogene diversifications, and four rate shifts, one for each of the four richest genera. Nonetheless, dating with the two priors provided similar age estimates for the divergence of cycads from Ginkgo (Carboniferous) and their crown age (Permian). Of these, Bayes factors clearly supported the birth-death prior.

Conclusions: These results suggest the choice of the branching process prior can have a drastic influence on our understanding of evolutionary radiations. Therefore, all dating analyses must involve a model selection process using Bayes factors to select between a Yule or birth-death prior, in particular on ancient clades with a potential pattern of high extinction. We also provide new insights into the history of cycad diversification because we found (i) periods of extinction along the long branches of the genera consistent with fossil data, and (ii) high diversification rates within the Miocene genus radiations.
\end{abstract}

Keywords: Bayesian relaxed-clock, Birth-death process, Branching process prior, Cycadales, Cycadopsida, Speciation tree prior, Yule model

"Cycads are to the vegetable kingdom what Dinosaurs are to the animal, each representing the culmination in Mesozoic times of the ruling Dynasties in the life of their age."

Lester Ward, 1900

\section{Background}

Our understanding of biotic evolution relies heavily on phylogenetic and dating reconstructions that provide insight into the periods of major diversification [1]. In the last decade, the advent of molecular dating approaches has fostered an explosion of studies constructing time-calibrated trees for diverse plant clades like bryophytes [2], ferns [3,4], gymnosperms [5-8] and angiosperms [9-11]. These dated trees have permitted the study of character evolution via the reconstruction of ancestral traits [11], inference of biogeographical history [7], as well as estimates of diversification rates

\footnotetext{
* Correspondence: fabien.condamine@gmail.com

${ }^{1}$ CNRS, UMR 7641 Centre de Mathématiques Appliquées (École

Polytechnique), Route de Saclay, 91128 Palaiseau, France

${ }^{2}$ Department of Biological and Environmental Sciences, University of

Gothenburg, Box 461, SE-405 30 Göteborg, Sweden

Full list of author information is available at the end of the article
} 
$[2,8,10]$. Dated trees are thus pivotal to our understanding of the evolution of plants, and of the groups that interact with them, such as herbivores and pollinators [12].

Despite the importance of reliable estimates of divergence times, our understanding of the temporal patterns of diversification remain in flux for many groups, in part because the methods for estimating evolutionary timescales from DNA sequences are being refined $[1,13,14]$. Since the introduction of relaxed-clock methods, which allow substitution rates to vary across the tree, a range of molecular dating methods has been developed. Bayesian inference has received the most attention because of the flexibility with which different parameters and prior assumptions can be incorporated, and the fact that priors are updated as part of the analysis [15,16]. The use of explicit prior distributions is central to the Bayesian perspective; however, the critical role of prior selection in Bayesian analysis is not always fully appreciated [17].

In Bayesian relaxed-clock (BRC) approaches, there are various types of priors, including priors on calibration points, branch-lengths, clock models, and branching processes. Priors on calibration points have been well studied [18] and, not surprisingly, the choice of these priors can affect estimates of node ages [19]. The effects of branch-length priors on posterior probabilities have been studied; priors assuming long internal branches cause high posterior probabilities [20]. In comparison, the impact of different branching process priors has been relatively under-explored [15,21].

The branching process prior (BPP), also called the 'tree shape' or 'speciation tree' prior, is a prior model on how trees are generated. Phylogenetic trees are the result of speciation and extinction events, and their relative roles can be varied and represented as different models of diversification [22]. These models effectively place a prior on how phylogenetic trees grow. Probability distributions over models of diversification were employed in some of the earliest attempts to use likelihood techniques to reconstruct genealogies [23]. The two most commonly used BPPs are the Yule (also called 'pure-birth') process, which models tree formation with a constant rate of speciation and no extinction, and the birth-death process, which includes speciation as well as a constant rate of lineage extinction. Birth-death priors have been used in Bayesian phylogenetics [24]; however, most published analyses use the Yule prior, perhaps because it was initially the only prior for the diversification process implemented in the widely used Bayesian software package BEAST [16]. Although the birth-death prior has recently been integrated into this software [25,26], many phylogenetic analyses still use the Yule prior (probably because the BEAST manual recommend the use of the Yule prior, see p. 10 of the BEAST manual, version 1.4). Few studies have used both priors in Bayesian dating, and even fewer have compared the impact of prior choice, even though recent studies have started to do so (e.g. [27]). One of the first to use both priors is the study of Couvreur et al. [28], who estimated the evolutionary history of the Brassicaceae using a BRC approach with both priors. Their age estimates did not differ under the Yule or birth-death diversification models, and both models fit the data equally well. While these results could be interpreted to mean that the BPP has little influence on BRC reconstruction in general, the Brassicaceae are a relative young group that originated in the Eocene (credibility interval 24.2-49.4 million years ago, $\mathrm{Ma}$ ) and likely did not experience major extinction events. However, choice of diversification prior might make a substantial difference for groups that have undergone significant extinction, and for which using a purebirth Yule prior could give in spurious results.

The cycads (Cycadopsida: Cycadales) are a plant group particularly well suited for testing the influence of BPPs on molecular dating. Today's species (331 species in the tropics and subtropics, [29]) are thought to represent the last remnants of their formidable past, and their evolutionary history extends back to the mid-Permian ( $270 \mathrm{Ma})$ [30-33]. Cycads have witnessed many drastic environmental changes [34-37] and likely suffered major periods of extinction [6,38]. Due to their richness and diversity in Mesozoic fossil records, their current diversity has long been assumed to be of relictual origin dating back to the Late Cretaceous [30,39-42]. This idea has been challenged by molecular time-calibrated phylogenies showing that long branches subtend late Cenozoic (in the Miocene $\sim 15 \mathrm{Ma}$ ) and near-simultaneous initiations of diversification of the living genera $[6,43]$.

Despite these recent studies, there remain dating uncertainties in the evolutionary history of cycads. At the generic level, some fossils suggest that the various radiations might be much older than the late Miocene (i.e. Eocene). Indeed, numerous pre-Miocene cycad fossils have been documented (e.g. [44-49]) that are likely early representatives of living genera. For example, recently described fossils from the early Cenozoic of China have been assigned to the crown-group of Cycas [50], but that assignment is doubtful given the extensive homoplasy in the characters used to link the fossils to the extant taxon [51]. Even if there is a possibility that fossils instead should be assigned to stem, they cast doubts on the dating. At the level of the whole group, different studies using similar fossil calibrations (but different taxon and molecular sampling) have produced different age estimates, notably for the origin of the cycad crown: $\approx 200 \mathrm{Ma}$ for Nagalingum et al. [6], and $\approx 230 \mathrm{Ma}$ for Salas-Leiva et al. [43]. Therefore further dating analyses are needed to estimate the cycad age and validate the recent generic radiations.

In reconstructing the phylogeny of cycads, Nagalingum et al. [6] sampled about two-thirds of all known species 
and used a molecular dataset composed of two chloroplast genes and one nuclear gene (although most of the taxa had the nuclear gene only). In addition to Penalized Likelihood and a strict molecular clock, they inferred the age and divergence times using the BRC approach implemented in BEAST, calibrated with four fossil constraints and a birth-death process as the BPP. The birth-death process used in the Bayesian analyses yielded a high ratio of extinction to speciation (relative death rate, 0.97) [6], suggesting a dominant role of extinction in shaping the phylogeny of cycads. Given our prior knowledge of cycad evolution gleaned from the fossil record, using a prior that includes extinction is realistic. However, Nagalingum et al. [6] did not assess the support of the birth-death prior versus other priors.

This study has four objectives: (i) investigating the impact of the BPP on the dating of ancient clades using the cycads as an example, (ii) assessing whether the birthdeath prior is statistically supported, (iii) studying the difference between the Yule and birth-death prior on our understanding of cycad diversification, and (iv) providing a cycad timetree reconciling fossil and phylogenetic data. We also discuss potential explanations for the differences obtained when using different priors and the consequences of prior choice for Bayesian molecular dating.

\section{Methods}

\section{Taxon sampling and molecular dataset}

We extended the molecular dataset of Nagalingum et al. [6] that initially contained 199 cycad species. We added molecular data for 38 additional species and the same genes retrieved from Genbank [52-57]. Our dataset comprises three genes covering two plastid genes: the maturase $\mathrm{K}$ (matK, 2,387 nucleotides, 82 taxa) and the ribulose 1,5-bisphosphate carboxylase large subunit (rbcL, 1,398 nucleotides, 80 taxa), and one nuclear gene: region 1 of phytochrome (PHYP, 1,802 nucleotides for 201 taxa). This resulted in a total of 237 species out of 331 described species $(71 \%)$, representing all extant genera with the following number of species per genus: 2 of the 2 Bowenia ( $B$. serrulata and B. spectabilis), 65 of the 107 Cycas, 24 out of 27 Ceratozamia, 8 of the 14 Dioon, all of the 65 Encephalartos, 2 of the 2 Lepidozamia (L. hopei and L. peroffskyana), 26 of the 41 Macrozamia, the monotypic Microcyas calocoma, the single Stangeria eriopus, and 43 out of 71 Zamia (including the junior synonym genus Chigua) (Figure 1). Following Nagalingum et al. [6], the dataset also included six species as outgroups: Ginkgo biloba (Ginkgoales), which is recognised as the sister lineage of cycads [58]; plus five conifer species (Abies firma, Araucaria heterophylla, Cryptomeria japonica, Pinus strobus and Pseudotsuga menziezii). The phylogenetic analyses were thus performed on a dataset containing a total of 243 species (of which 237 are cycads) and 5587 nucleotides. The information on each sampled species is presented on Additional file 1: Table S1.

\section{Fossil calibrations}

To calibrate the cycad tree, we used two fossil datasets. First, we followed Nagalingum et al. [6] and used four cycad fossil constraints (FC1-4), which were retrieved from a careful examination of the cycad fossil record ([32]; Figure 1). These four fossils have also been used by Salas-Leiva et al. [43]. Hereafter this fossil dataset is referred to as the 'traditional fossil dataset' (FC1-4). Second we used these four fossils and added two fossils based on the phylogenetic analyses of Hermsen et al. [32] and Martínez et al. [59]. The fossil record was reexamined after new fossils from the Cretaceous were discovered, which did not affect overall fossil assignments, but allowed the use of new fossils to calibrate the cycad tree [59], two of which are tentatively used here. Hereafter this fossil dataset is referred to as 'new fossil dataset' (FC1-6).

Based on the presence of synapomorphies linking the fossils to the extant clades, all fossils were used as minimum age constraints for specific nodes ([32,59], Figure 1). However, since synapomorphies can evolve anywhere along the stem branch and the fossil may attach anywhere along this branch [60], we used a commonly employed approach whereby the fossils constrain the stem rather than crown node $[61,62]$. The absolute fossil ages we used (detailed below) are slightly different from those used in Nagalingum et al. [6], mainly due to an updated geological timescale [63]. Dating fossils older than $\sim 50,000$ years is difficult, which means that those fossils are typically assigned to a stratigraphic interval, for example, the late Miocene. The ages assigned below are the ages of the youngest of the boundaries of stratigraphic interval within which the fossil was found (the fossil will actually be older than this age designation).

\section{Cycad stem ( $F C 1$, Younger $=265.1 \mathrm{Ma}$ and Older $=364.7 \mathrm{Ma}$ )}

The oldest possible records of the group Cycadophyta are microstrobili (e.g. [64]) and megasporophylls (e.g. [65,66]), of which +Crossozamia (eight known species) is the least equivocal in terms of phylogenetic affinity $[32,59,66]$. Crossozamia consists of megasporophylls with similar morphology to the extant Cycas [65,66]. Although Hermsen et al. [32] identified Crossozamia as being sister to Cycas, the two characters supporting this relationship do not provide strong evidence for Crossozamia belonging to crown group cycads [59]. In addition, the loosely aggregated cone is most probably an ancestral state within cycads. Therefore the divergence between cycads and Ginkgo biloba was constrained using Crossozamia. The age for the host rock formation (Shihhotse) 


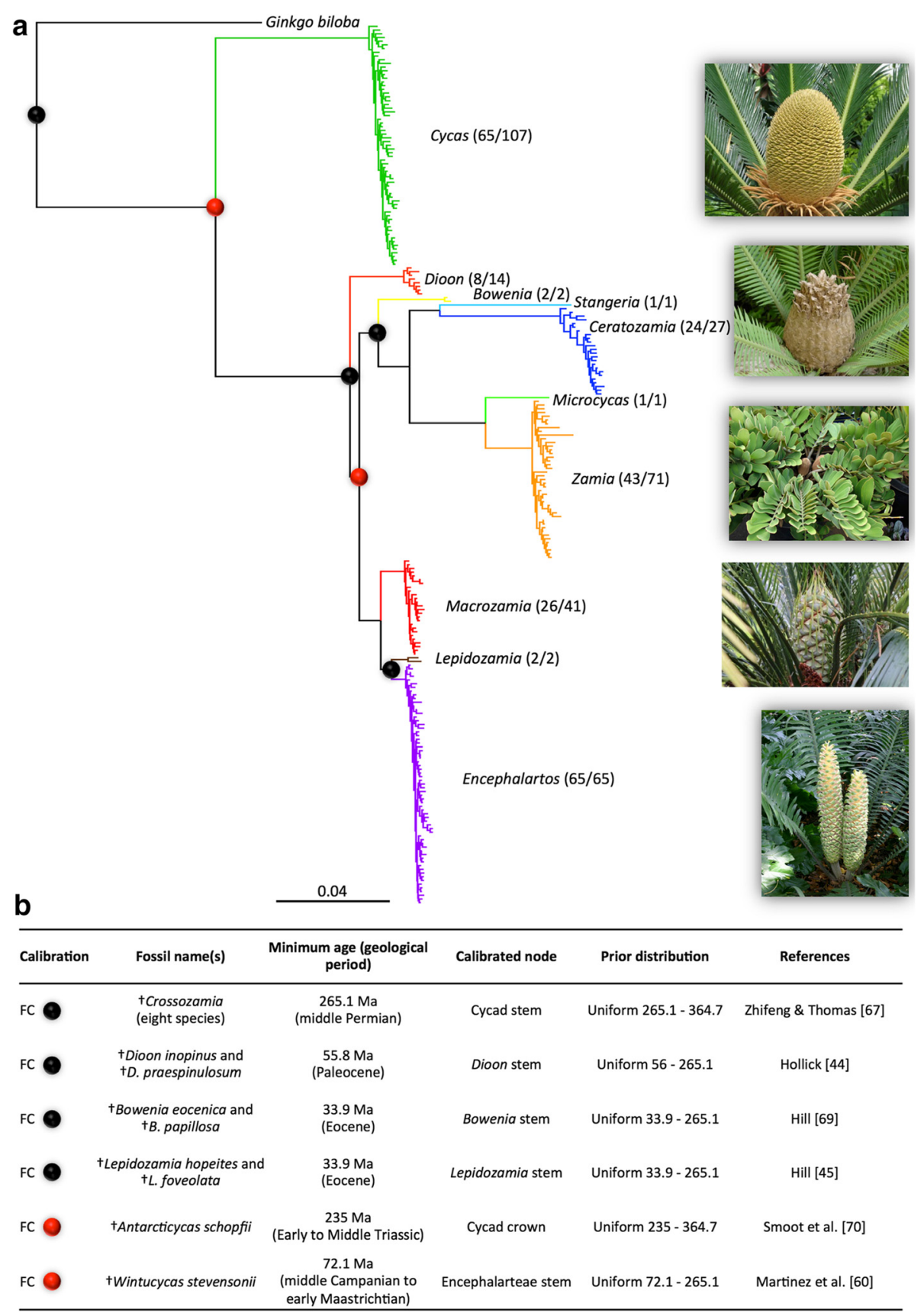

Figure 1 The node calibration procedure used for dating the cycads. (a) Phylogenetic tree of cycads showing the relationships among the 10 genera. Genera are represented by triangles proportional to their species richness. Numbers in parenthesis are the number of species sampled, and the total number of species, within each genus. Pictures illustrate Cycas, Dioon, Zamia, Macrozamia, and Encephalartos species. Black dots indicate the four 'traditional' fossil calibrations used for dating, and red dots indicate the two new fossil calibrations evaluated in this study. (b) Information related to the four fossil calibrations (FC, see the text for more details). Ma, million years ago.

that preserves the Crossozamia fossils was initially described as lower Permian, but the age of the Shihhotse Formation has been revised to the Roadian-Wordian (265.1-272.3; [63]) in the middle Permian [67]. We used the minimum age of this time interval $(265.1 \mathrm{Ma})$ as a minimum age for the stem of cycads. This age was also used as a conservative maximum possible age for the nodes with internal fossil calibrations (FC2-FC4).

Dioon stem $(F C 2$, Younger $=56 \mathrm{Ma}$ and Older $=265.1 \mathrm{Ma})$

The origin of the stem group of Dioon was constrained by fossil leaves of $+D$. inopinus and $+D$. praespinulosum 
[44], which have synapomorphies consistent with the leaflet venation anastomoses and leaflet insertion on the rachis of extant Dioon [32]. While originally described as Eocene by Hollick [44], a more recent interpretation of the composition of the Hamilton Bay flora (Kootznahoo Formation), Kupreanof Island, Alaska, from which fossils of both Dioon were originally described, suggest they are of Paleocene age [6,32]. Therefore the Dioon stem was assigned a minimum age of $56 \mathrm{Ma}$ [63].

Bowenia stem (FC3, Younger $=33.9 \mathrm{Ma}$ and Older $=265.1 \mathrm{Ma}$ ) Bowenia leaf fossils of $+B$. eocenica and $+B$. papillosa [68], both found in Australia, were used to constrain the divergence of Bowenia from other genera. These fossils were identified as members of the extant genus based on cuticular characters (i.e. number of subsidiary cells) and leaflet morphology (i.e. venation and serrated margin). Both fossil species were found in Australian Eocene deposits (at Anglesea, Victoria for $+B$. eocenica, and at Nerriga, New South Wales for $+B$. papillosa), which confers a minimum age constraint at $33.9 \mathrm{Ma}$ for the Bowenia stem [63].

\section{Lepidozamia stem $(F C 4$, Younger $=33.9 \mathrm{Ma}$ and Older $=265.1 \mathrm{Ma}$ )}

Fossil Lepidozamia leaves of $+L$. hopeites and $+L$. foveolata are also from Australia [45]. Fossils of this genus can be identified by cuticular characters (orientation of the epidermal cells relative to axis of the pinna) that are unique to Lepidozamia and support affinity to the extant genus [32,45]. Found in the Australian Eocene (at Nerriga, New South Wales for $+L$. foveolata), this set a minimum age of 33.9 Ma for the Lepidozamia stem [63].

Cycad crown (FC5, Younger $=235 \mathrm{Ma}$ and Older $=364.7 \mathrm{Ma})$ The age of modern cycads can be calibrated with †Antarcticycas schopfii [69]. The fossil Antarcticycas has been extensively studied [32,70]. A reconstruction of the plant habit has even been proposed [70]. This makes Antarcticycas the most completely known of the extinct Triassic cycad taxa, if not of all fossil cycads, due to the presence of anatomically preserved organs [70]. Interestingly, phylogenetic studies have also tentatively assigned Antarcticycas within modern cycads, and close to the crown of cycads [32,59]. None of the extant genera are phylogenetically sister to Antarcticycas, which makes it a valuable fossil calibration for the crown of cycads. Antarcticycas was found in the Fremouw Formation of the early Middle Triassic of Antarctica. We used a conservative age of the Middle Triassic, i.e. $235 \mathrm{Ma}$ [63], although there remains uncertainty on the true age of the Fremouw Formation with some authors suggesting an Anisian age (242-247.2 Ma).

\section{Encephalarteae stem (FC6, Younger $=72.1 \mathrm{Ma}$ and Older $=265.1 \mathrm{Ma}$ )}

Many fossils have been attributed to the tribe Encephalarteae based on morphological and phylogenetic evidence [32,59]. Among them the recently discovered +Wintucycas stevensonii [59] is one of the best-known fossils. Wintucycas has features that clearly allow us to assign it to Encephalarteae due to their manoxylic wood, centripetal polyxyly, parenchymatous pith, centrifugal polyxyly and medullary vascular bundles. Wintucycas was found in the Allen Formation (middle Campanian to early Maastrichtian) of the Late Cretaceous of Argentina (Patagonia), providing a minimum age for the stem of Encephalarteae at 72.1 Ma [63].

\section{Tree root height}

The tree root height is the divergence between Cycadales and Ginkgoales. Following Clarke et al. [62], a maximum age can be established with the first records of seeds in the form of preovules that satisfy the criteria of the seed habit. These criteria are the possession of a single functional megaspore that is enveloped in a nucellus (considered equivalent to the megasporangium), which is surrounded (to some extent) by an integument or preintegument and has mechanisms enabling the capture of pollen before seed dispersal [62,71]. All the criteria are first met with †Elkinsia polymorpha found in the VCo spore Biozone, Evieux Formation [71] in the Fammenian (Late Devonian). The VCo spore Biozone spans 364.7360.7 Ma [63]. A maximum age for gymnosperms is thus 364.7 Ma. We also used this age to set maximum ages for the cycad stem (FC1) and crown (FC5).

\section{Phylogenetic reconstructions}

To obtain a starting tree for the dating analyses, Bayesian inferences were performed with MrBayes 3.2.3 [72]. To determine the best-fit partitioning scheme of molecular evolution for our dataset, we used PartitionFinder 1.1.1 [73]. For the PartitionFinder analyses, branch lengths were unlinked to allow them to be independently estimated for each partition. The searched for best model, among those available in MrBayes, was performed under the greedy algorithm based on the Bayesian Information Criterion model metric. We used the partitioning scheme and among-site rate variation suggested by PartitionFinder, but instead of selecting one substitution model a priori, we used reversible-jump Markov Chain Monte Carlo (rjMCMC) to allow sampling across the entire substitution rate model space [74].

MrBayes analyses consisted of four rj-MCMC running for 100 million generations with sampling every 10,000 generations and the first $25 \%$ discarded as burn-in. We specified ( $i$ ) a uniform prior probability of phylogenies (i.e. all possible trees are considered a priori equally probable), 
and (ii) a uniform prior probability distribution on branch lengths. The convergence of the runs was assessed by checking the potential scale reduction factor (PSRF) values of each parameter in MrBayes and the Effective Sample Size (ESS) values of each parameter in Tracer 1.6 [75]. Values of PSRF close to 1.00 and ESS above 200 were considered as good indicator of convergence. Nodes recovered with posterior probabilities $(\mathrm{PP}) \geq 0.95$ are considered to be strongly supported.

\section{Bayesian relaxed-clock analyses}

For all dating analyses, we used the BRC approach as implemented in BEAST 1.8 [26]. BEAUti 1.8 was used to create the BEAST input file. We implemented partitioned relaxed-clock models with an uncorrelated lognormal clock model that assumes an underlying lognormal distribution (UCLD) of the evolutionary rates [16], which is more likely to yield accurate estimates than the uncorrelated relaxed clock model that assumes an exponential distribution of the evolutionary rates [76]. We used the same nucleotide substitution model as for the MrBayes analyses. Given that one of the main goals of the study was to investigate the impact of the BPP on molecular dating, we set the tree prior in BEAST to either the Yule or the birth-death process [23]. Following the rigorous approach of Vanneste et al. [77], we utilized the following priors: a uniform prior between 0 and 10 with a starting value at 0.1 for the Yule birth rate and birth-death mean growth rate, and a uniform prior between 0 and 1 with a starting value at 0.5 for the birth-death relative death rate. We used an exponential prior with mean one-third on the standard deviation of the UCLD model, and a uniform prior between 0 and 1 on the mean of the UCLD model. Fossil calibrations were conservatively set with a uniform distribution bounded by the minimum and maximum ages as explained above. A starting tree with branch lengths satisfying all of the fossil prior constraints was inserted, as derived from the MrBayes analyses (described above) [77]. The 'tree operators' of the BEAST tree model were disabled to keep the topology fixed so that only the branch lengths were optimized. This procedure ensures better convergence of the tree topology ( $\mathrm{S}$. Ho, pers. comm.). Other parameters were kept to their default prior distribution or were indirectly specified through other parameters.

We designed four distinct BEAST analyses by mixing the fossil dataset and the BPP as follows (i) use of the 'traditional fossil dataset' and the Yule model as BPP; (ii) use of the 'traditional fossil dataset' and the birth-death process as BPP; (iii) use of the 'new fossil dataset' and the Yule model as BPP; and (iv) use of the 'new fossil dataset' and the birth-death process as BPP. For each fossil dataset, we included all fossils for dating the tree, and did not perform cross-validation analyses because
Warnock et al. [78] questioned the cross-validation approach to measure consistency among calibrations based on minimum constraints $[61,79]$. The most effective means of establishing the quality of fossil-based calibrations is through a priori evaluation of the intrinsic palaeontological, stratigraphic, geochronological and phylogenetic data [78], which we describe above.

The MCMC analyses were run for 100 million generations and sampled every 10,000 generations, resulting in 10,000 trees in the posterior distribution; we discarded the first 2,500 trees as burn-in. We used BEAGLE [80], a library for high-performance statistical phylogenetic inference, with default parameters. This allowed a faster and more accurate computation of likelihood models within our BEAST analyses. All BEAST analyses were performed on the computer cluster CIPRES Science Gateway 3.3 ([81]; http://www.phylo.org/). Tracer was used to assess graphically the convergence of runs, and to check the ESS for all parameters (indicated by ESS above 200). For each analysis, we conducted two independent runs to ensure convergence of the MCMC. Post burn-in trees from the two distinct runs $(7,500$ trees for each run) were further combined to build the maximum clade credibility tree.

In Bayesian analyses, models have traditionally been compared using the harmonic mean estimate (HME). Other approaches have been developed to calculate accurately the marginal likelihood estimate (MLE) of the specified model, such as path sampling (PS) [82] and stepping-stone sampling (SS) [83]. PS and SS substantially outperform the HME estimator, which overestimates the marginal likelihood and fails to select reliably the best model [76]. We performed MLE using SS with 150 path steps, each with a chain length of one million iterations (G. Baele, pers. comm.), and other parameters were set by default. We directly calculated the log-Bayes factors (hereafter BF) [76,84] from MLEs, and used BF to compare the support of the Yule and the birth-death processes for a given calibration strategy. We considered $\mathrm{BF}$ values above 5 to indicate that one model was significantly favoured over another [84].

\section{Macroevolutionary rates through time}

We used the Bayesian Analysis of Macroevolutionary Mixture (BAMM, www.bamm-project.org) to estimate speciation and extinction rates through time and among/ within clades [85-87]. BAMM is an analytical tool for studying complex evolutionary processes on phylogenetic trees, potentially shaped by a heterogeneous mixture of distinct evolutionary dynamics of speciation and extinction across clades. The method uses rj-MCMC to detect automatically rate shifts and sample distinct evolutionary dynamics that best explain the whole diversification dynamics of the clade. Within a given regime, evolutionary 
dynamics can involve time-variable diversification rates; in BAMM, the speciation rate is allowed to vary exponentially through time while extinction is maintained constant [86]. Subclades in the tree may diversify faster (or slower) than others, and BAMM detects these diversification rate shifts without a priori hypotheses on how many and where these shifts might occur. BAMM provides estimates of marginal probability of speciation and extinction rates at any point in time along any branch of the tree. Marginal probabilities of the number of evolutionary regimes can also be computed, allowing comparisons of models with a given number of shifts with BF.

Estimating extinction rates from reconstructed phylogenies is notoriously difficult [88-90], although not impossible (see Box 3 of Morlon [22] for a discussion of the subject, and ref. [91-94] for recent papers contradicting the widespread idea that extinction rates cannot be estimated from molecular phylogenies). The developer of the approach cautions that BAMM estimates of extinction should be taken with care [87], because they are sensitive to the choice of the prior and have large confidence intervals. Still, these estimates are well correlated with the underlying rates (Figure five B in Rabosky [87]). Biases in extinction rate estimates often come from fitting models based on underlying hypotheses that are violated in nature, such as fitting models with homogeneous rates across clades when major rate shifts occurred (see ref. [90,93], but see [94]). The BAMM approach should in principle help with these issues, because it explicitly accounts for rate heterogeneity across clades while allowing rates to vary over time [85-87]. We share Beaulieu and O'Meara's view [94] that we should use prudent caution, but not abandon all hope, of estimating extinction from molecular phylogenies. Hence, we think that it is crucially important to assess the effect of BPP prior choice on these estimates, and to discuss them in the light of what is known from the cycads fossil record.

BAMM is implemented in a $\mathrm{C}++$ command line program and the BAMMtools R-package [87]. We ran BAMM analyses on the timetree calibrated with the 'new-fossils dataset', and reconstructed with either the Yule or the birth-death prior. We set four rj-MCMC running for 50 million generations and sampled every 50,000 generations. A compound Poisson process is implemented in BAMM for the prior probability of a rate shift along any branch. We used a prior value of $1.0 \mathrm{im}-$ plying a null hypothesis of no rate shift across the phylogeny, as recommended by Rabosky [87]. We accounted for incomplete taxon sampling using the implemented analytical correction, with a sampling fraction set to 0.716 (i.e. 237 species out of the 331 described species). We performed four independent runs (with a burn-in of $10 \%)$ using different seeds, and we used ESS to assess the convergence of the runs, considering values above 200 as indicating convergence. The posterior distribution was used to estimate the configuration of the diversification rate shifts; alternative diversification models were compared using BF. To complement these analyses, we computed pairwise probabilities that any two lineages or clades share a common set of macroevolutionary rate parameters, using the macroevolutionary cohort analysis implemented in BAMM [87].

\section{Results}

\section{Phylogeny of cycads}

Tracer plots indicated that MrBayes runs reached convergence before 10 million generations (results not shown). Convergence of the analyses was also supported by the average standard deviation of split frequencies $(<0.01)$, all PSRF values close to 1.0 (range between 0.999 and 1.019), and ESS values above 200 (with many $>1000$ ) for the post burn-in trees. The resulting Bayesian trees were well resolved: all nodes of the backbone tree and genus crown nodes were recovered with maximal posterior probabilities $(\mathrm{PP}=1$, Figure 1 and Additional file 2: Figure S1). Only nodes within genus radiations were recovered with lower PP, which was expected because the genetic divergence among cycad species within genera is low (Cycas: [95,96]; Ceratozamia: [52]; Dioon: [56]; Encephalartos: [97]; Macrozamia: [98]; Zamia: [99]). Our MrBayes analyses are congruent with the results of Nagalingum et al. [6], but differ from other studies $[43,54,55,100]$. Notably the genus Bowenia is found as sister to the clade ((Ceratozamia, Stangeria), (Microcycas, Zamia)) as in Nagalingum et al. [6], but an alternative position is that Bowenia is sister to all genera, except Cycas and Dioon [43].

\section{Divergence time estimates and model selection for the branching process prior}

Convergence of the dating analyses was ensured by ESS values above 200 for all parameters (with many >1000) for the post burn-in trees (Table 1) and Tracer plots indicated that BEAST runs reached convergence before the burn-in threshold. The choice of branching process prior had a striking effect on age estimates (Figures 2 and 3; Table 1). Analyses with the Yule prior inferred much older ages for cycad genera (Figure 4). Genuslevel crown ages were on average three times older with a Yule than with a birth-death prior (3.2-fold difference with the 'traditional fossil dataset' and 2.9-fold with the 'new fossil dataset'). This difference was quite striking, with non-overlapping credibility intervals (95\% highest posterior density) for the genus crown ages (Figure 4). Generic stem ages and some ages of deeper nodes were also inferred to be older with the Yule than with the birth-death prior, although the difference was not as 
Table 1 Age estimates for the six nodes subtending a fossil calibration (FC)

\begin{tabular}{|c|c|c|c|c|c|c|c|c|c|c|c|}
\hline \multirow[t]{2}{*}{$\begin{array}{l}\text { Fossil } \\
\text { calibration } \\
\text { strategy }\end{array}$} & \multirow[t]{2}{*}{ Prior } & \multirow[t]{2}{*}{ HME } & \multirow[t]{2}{*}{ MLE (SS) } & \multirow[t]{2}{*}{$\begin{array}{l}\text { ESS } \\
\text { (logL) }\end{array}$} & \multirow[t]{2}{*}{$\mathrm{BF}$} & \multirow{2}{*}{$\begin{array}{l}\text { Cycad } \\
\text { stem } \\
\text { (FC1) } \\
\text { min. age } \\
265.1 \mathrm{Ma}\end{array}$} & \multirow{2}{*}{$\begin{array}{l}\text { Dioon } \\
\text { stem } \\
\text { (FC2) } \\
\text { min. age } \\
56 \mathrm{Ma}\end{array}$} & \multirow{2}{*}{$\begin{array}{l}\text { Bowenia } \\
\text { stem } \\
\text { (FC3) } \\
\text { min. age } \\
33.9 \mathrm{Ma}\end{array}$} & \multirow{2}{*}{$\begin{array}{l}\text { Lepidozamia } \\
\text { stem } \\
\text { (FC4) } \\
\text { min. age } \\
33.9 \mathrm{Ma}\end{array}$} & \multirow{2}{*}{$\begin{array}{l}\text { Cycad } \\
\text { crown } \\
\text { (FC5) } \\
\text { min. age } \\
235 \mathrm{Ma}\end{array}$} & \multirow{2}{*}{$\begin{array}{l}\text { Encephalarteae } \\
\text { stem } \\
\text { (FC6) } \\
\text { min. age } \\
72.1 \mathrm{Ma}\end{array}$} \\
\hline & & & & & & & & & & & \\
\hline \multirow{2}{*}{$\begin{array}{l}\text { Traditional } \\
\text { fossil } \\
\text { dataset }\end{array}$} & Birth-death & 6343.61 & -26828.83 & 2451 & 26.7 & $\begin{array}{l}316.6 \\
{[269.5-363.3]}\end{array}$ & $\begin{array}{l}140 \\
{[90-192.9]}\end{array}$ & $\begin{array}{l}116.3 \\
{[76.7-160.8]}\end{array}$ & $\begin{array}{l}38.1 \\
{[33.9-50.9]}\end{array}$ & $\begin{array}{l}257.2 \\
{[184.3-337.5]}\end{array}$ & $\begin{array}{l}129.2 \\
{[84.3-180.2]}\end{array}$ \\
\hline & Yule & -26330.62 & -26855.49 & 3835 & & $\begin{array}{l}295.7 \\
{[265.1-350.1]}\end{array}$ & $\begin{array}{l}206.4 \\
{[161.2-258.2]}\end{array}$ & $\begin{array}{l}170.3 \\
{[130.8-216.3]}\end{array}$ & $\begin{array}{l}68 \\
{[41.7-100.4]}\end{array}$ & $\begin{array}{l}277.2 \\
{[231-344.9]}\end{array}$ & $\begin{array}{l}190.4 \\
{[146.9-240.2]}\end{array}$ \\
\hline \multirow[t]{2}{*}{$\begin{array}{l}\text { New fossil } \\
\text { dataset }\end{array}$} & Birth-death & -26343.36 & -26825.04 & 2076 & 36.3 & $\begin{array}{l}323.2 \\
{[273.9-364.6]}\end{array}$ & $\begin{array}{l}156.1 \\
{[107-207.9]}\end{array}$ & $\begin{array}{l}129.7 \\
{[88.7-174.3]}\end{array}$ & $\begin{array}{l}39.1 \\
{[33.9-55]}\end{array}$ & $\begin{array}{l}274.5 \\
{[235-332.4]}\end{array}$ & $\begin{array}{l}144.5 \\
{[97.7-192.5]}\end{array}$ \\
\hline & Yule & -26331.16 & -26861.34 & 1361 & & $\begin{array}{l}296.9 \\
{[265.1-351.7]}\end{array}$ & $\begin{array}{l}203.5 \\
{[158.6-253.6]}\end{array}$ & $\begin{array}{l}169.5 \\
{[129.4-214.2]}\end{array}$ & $\begin{array}{l}67.8 \\
{[40.6-102]}\end{array}$ & $\begin{array}{l}280.1 \\
{[235.6-334.8]}\end{array}$ & $\begin{array}{l}188 \\
{[143.6-235.6]}\end{array}$ \\
\hline
\end{tabular}

Absolute ages and their credibility intervals were obtained for the two pairs of Bayesian calibration strategies, using either the Yule or the birth-death model as branching process prior.

Values are the median ages and 95\% Highest Posterior Density (HPD). We denote HME: harmonic mean estimate; MLE (SS): marginal likelihood, estimated with the stepping-stone sampling; ESS: effective sample size; BF: Bayes factor (BF), computed as the difference between the MLE of the birth-death and the Yule prior. A positive value indicates support for the birth-death prior.

marked as in the case of the genus crown ages (Figure 5). However, the birth-death and Yule priors usually inferred similar ages for the cycad stem and crown ages (Figure 5). Analyses with the birth-death process inferred a very high estimate of the relative extinction rate (ratio of extinction to speciation, or turnover) with a median $=0.966$ for the dating with four FC (95\% HPD $0.9255-0.9972$ ), and a median $=0.962$ for the dating with six FC (95\% HPD 0.9153-0.9947).

Bayes factor values, calculated with the marginal likelihood estimates of the stepping-stone analyses, support the birth-death process as the best tree prior (Table 1). Of the two pairs of BEAST analyses (four FC and six FC), BF values are above the standard threshold: $\mathrm{BF}_{4 \mathrm{FC}}=26.66$ between the Yule and birth-death prior, and $\mathrm{BF}_{6 \mathrm{FC}}=36.3$ between the Yule and birth-death prior. On the contrary, the HME found the opposite, that is the Yule model is the best prior for both datasets for all analyses (Table 1). The results for the cycads thus support previous results showing that the HME estimator is not reliable [76].

\section{Macroevolutionary rates through time}

The BAMM analyses converged for both trees $\left(\mathrm{ESS}_{\text {Yule }}=\right.$ 719.6, Additional file 3: Figure S2; $\mathrm{ESS}_{\text {birth-death }}=750.6$, Additional file 4: Figure S3). The choice of the BPP had a major influence on the number of different evolutionary regimes detected in the history of the cycads, as well as on the estimation of speciation and extinction rates across the tree (Figure 6). Analyses with the Yule prior supported a model with three evolutionary regimes (i.e. two rate shifts, Additional file 5: Figure S4) located at the crown of the genera Cycas and Encephalartos (according to BF values $>10$, and $B F=154.5$ over the null model). On the other hand, analyses with the birth-death prior supported a model with five evolutionary regimes (i.e. four rate shifts,
Additional file 6: Figure S5) located at (or near) the crown of the four most species-rich genera (according to $\mathrm{BF}$ values $>10$, and $\mathrm{BF}=29.3$ over the null model). Moreover, both speciation and extinction rates estimated with the birth-death prior are twice as high as those estimated with the Yule prior (see scales on Figure 6). The credible set of shift configurations with the highest posterior probabilities is provided in Additional file 7: Figure S6 for each tree. The best configuration shift is provided in Additional file 8: Figure S7 for each tree. The macroevolutionary cohort analyses showed distinct evolutionary trajectories for the four richest cycad genera with the birth-death prior (Additional file 9: Figure S8), but not with the Yule prior (Additional file 10: Figure S9).

\section{Discussion}

The branching process prior impacts Bayesian divergence time estimates

Our Bayesian dating analyses highlight an important effect of the branching process prior on the divergence times of cycads. Dating with the Yule prior consistently inferred ages for genus crown groups that were about three times older than those obtained with the birth-death prior. The cycad tree dated with the birth-death process suggested the initiation of crown radiations of the species-rich genera in the Neogene, whereas the Yule model indicated that the radiations began in the Paleogene. These differences in crown ages are noteworthy because the $95 \%$ credibility intervals for these nodes did not overlap. It is important to note that the effect of BPP is reduced towards the origin of cycads since, for both priors, genus radiations are subtended by long stem branches originating in the Triassic or Permian. This pattern is recovered for both calibration strategies. Therefore, the BPP is an important influence on the Bayesian dating analyses. 


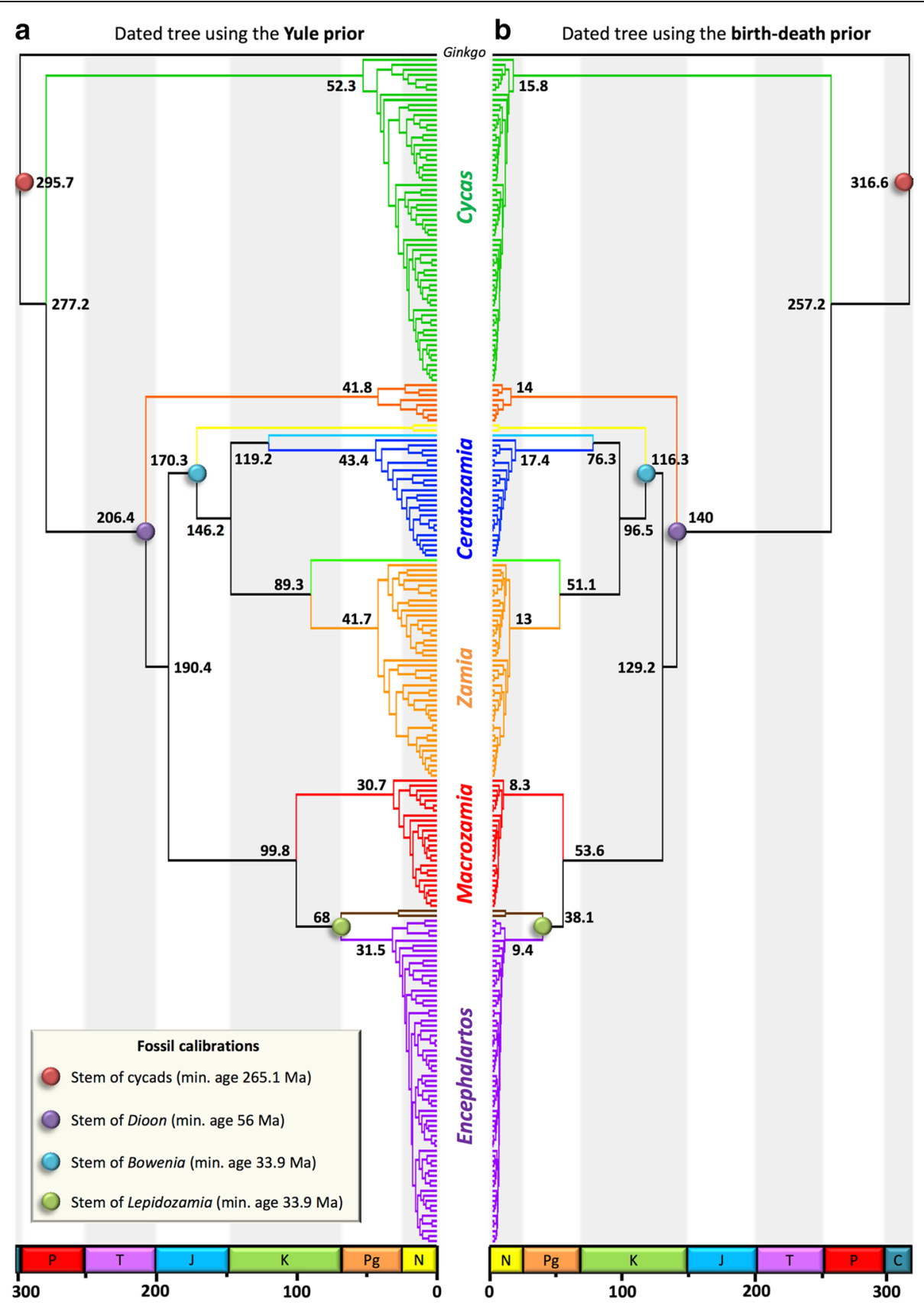

Figure 2 Time-calibrated phylogeny of Cycadales obtained with the four fossil calibrations. Timetree obtained with the Yule (a) or the birth-death (b) model as branching process prior. Each tree is the maximum clade credibility tree with median ages from the Bayesian analyses. The coloured dots highlight nodes on which fossil age constraints were applied. Values are median age estimates for the main nodes, in million years. C, Carboniferous; P, Permian; T, Triassic; J, Jurassic; K, Cretaceous; Pg, Paleogene; N, Neogene. The last geological period, the Quaternary, is missing.

\section{Potential causes of age differences between branching process priors}

It is unclear why differing tree priors have a major impact on divergence time estimates. The priors differ principally in the inclusion of an extinction rate. In the Yule prior, there is no extinction, but in the birth-death prior there is a parameter for the extinction rate. The effect of extinction in the birth-death prior is that there are relatively greater nodes toward the present compared to the past, because extinction has not yet had an effect on the more recent nodes, this phenomenon is known as the "pull of the present" [25]. This pattern could explain the contrasting results found when dating the cycad phylogeny with a birth-death versus a Yule prior. Support for the birth-death prior includes fossil evidence indicating that extinctions occurred and were important 


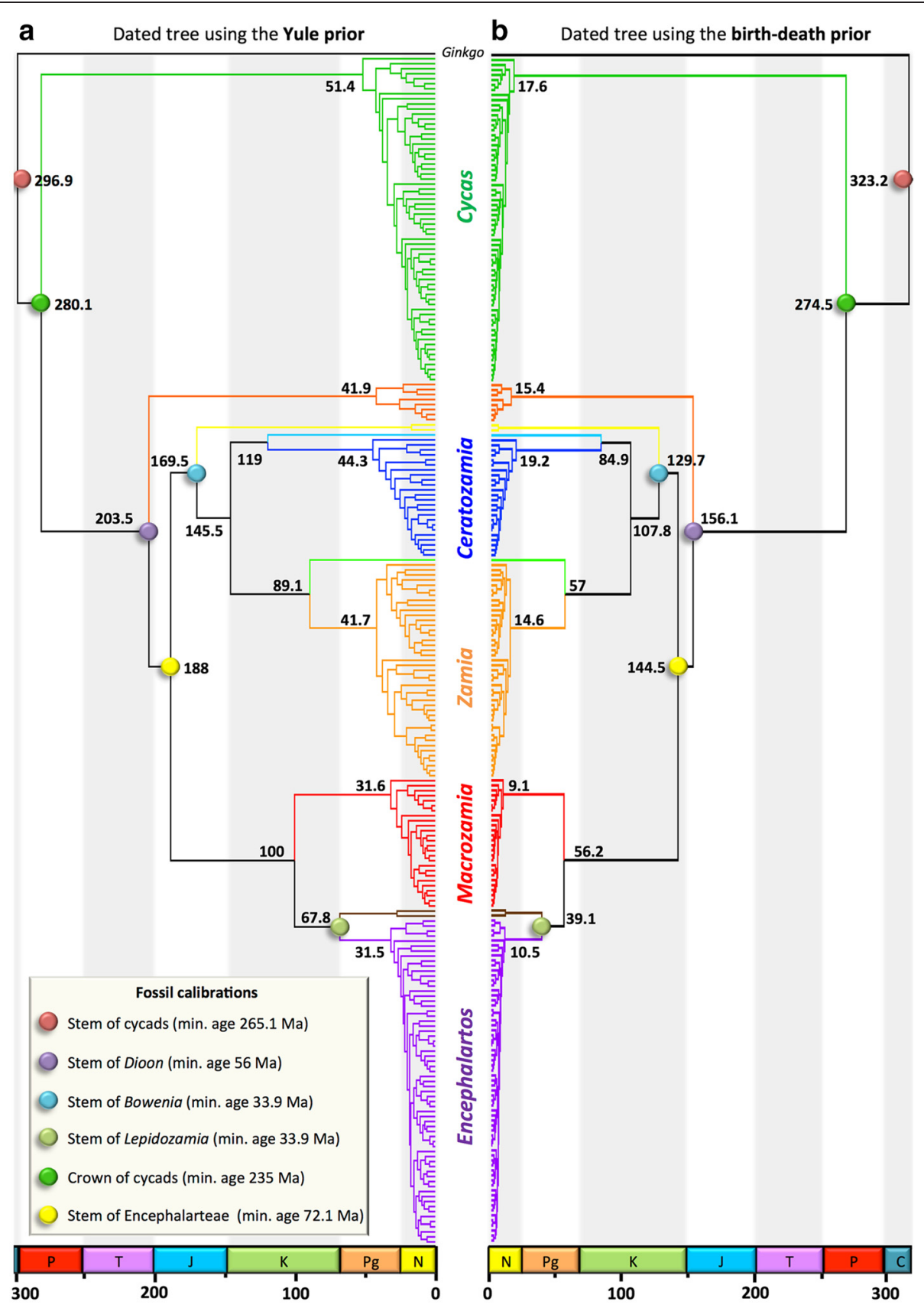

Figure 3 Time-calibrated phylogeny of Cycadales obtained with the six fossil calibrations. Timetree obtained with Yule (a) or the birth-death (b) model as branching process prior. Each tree is the maximum clade credibility tree with median ages from the Bayesian analyses. The coloured dots highlight nodes on which fossil age constraints were applied. Values are median age estimates for the main nodes, in million years. C, Carboniferous; P, Permian; T, Triassic; J, Jurassic; K, Cretaceous; Pg, Paleogene; N, Neogene. The last geological period, the Quaternary, is missing.

in shaping cycad evolution. More generally, extinction is a dominant feature of life given that $99.9 \%$ of all species that ever existed are now extinct [101]. But the role and effect of extinction could also potentially explain why the effect of BPPs appears to be taxon specific (i.e. little effect in Brassicaceae [28]). Indeed, it is possible that older clades might be more sensitive to the BPP choice because extinction is likely to be a more important component of their evolutionary histories. Earlier simulations and empirical studies have indicated that our understanding of the statistical properties of the diversification prior combined with prior distribution of calibrations is incomplete, particularly when the tree topology is considered $[78,102,103]$. It is an open question as to how important BPP choice will be for other groups, but further analyses of additional taxa as well as 


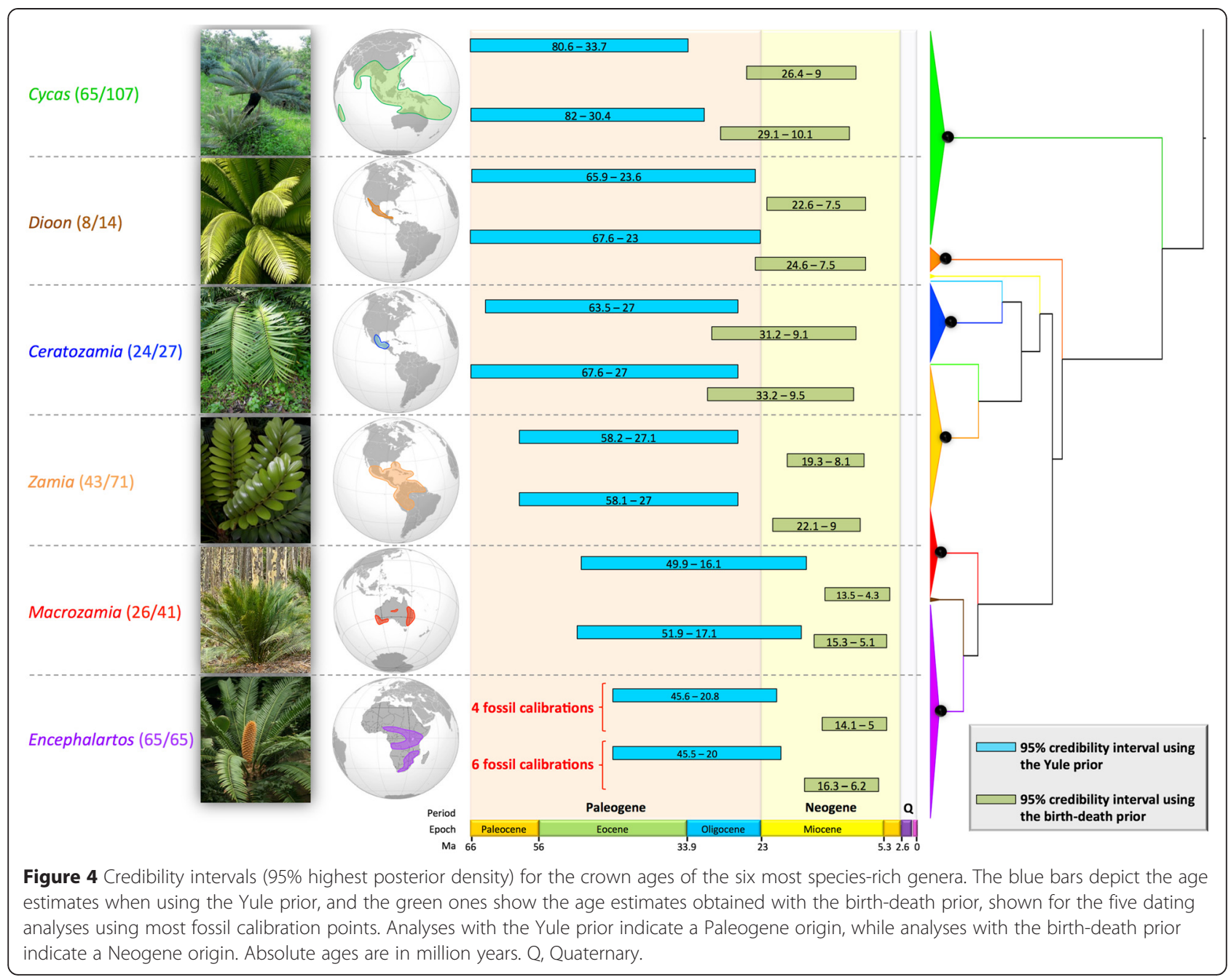

simulation studies will be valuable in understanding the detailed effects that tree priors have on age estimates.

\section{Other potential biases in the branching process priors}

While accounting for extinction in BPP priors is an important first step, a birth-death model with homogeneous rates across time and across the various clades within large groups is still an oversimplified model of their evolution. In particular, the hypothesis of rate homogeneity is thought to strongly bias extinction rate estimates $[90,93]$. We suggest that more complex priors should be developed for implementation in dating software; indeed evidence for age- or time-dependent diversification in numerous clades have resulted in development of methods to take into account rate-heterogeneity through time and clades $[93,104]$.

Another potential bias in BPP priors is the use of models assuming complete or uniform sampling. Phylogenies are often sparsely sampled, particularly in longbranched outgroups. Sparsely sampled outgroups violate the basic assumption of most (if not all) the tree priors implemented in Bayesian dating, namely that the taxon sampling is random and consistent across all clades in the tree (see p. 98 of Drummond and Bouckaert [105]). In this case, it is difficult to find appropriate priors describing the tree: neither the single-parameter Yule model nor the two-parameter birth-death model fit a situation in which some parts of the tree are densely sampled, while others consist of a single long-branched species (i.e. Ginkgo versus the cycads).

\section{Implications for Bayesian dating analyses}

The vast majority of molecular dating studies using BEAST have relied on the Yule model, although some recent studies have used both the Yule and birth-death process $[27,28,106]$. However these studies did not find any differences in age estimates between the two models, nor they did not perform MLE and Bayes factors analyses. Here we tested competing evolutionary hypotheses using a Bayesian relaxed-clock under two different branching priors, and we 


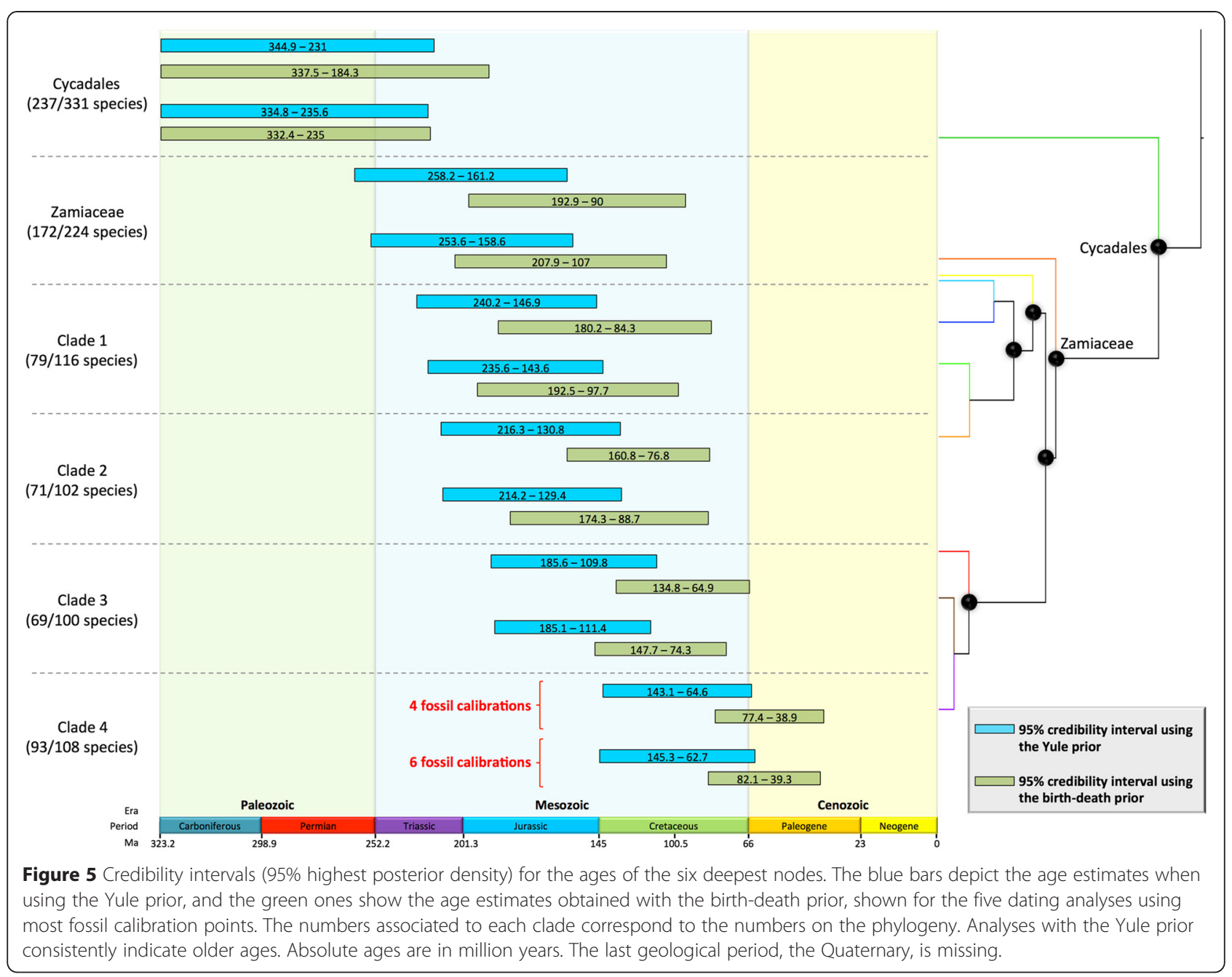

found stronger support for the birth-death than the Yule process as a prior to reconstruct the cycad tree.

Model selection is a necessary step, because as in the case of cycads, prior choice can have important implications if one simply reconstructs the tree using a Yule model as commonly performed. Conclusions on the age, diversification and/or biogeographic patterns might be different regarding the BPP (see below). Supposedly ancient plant clades might be affected by prior choice as for cycads; specifically, clades with an old and welldocumented fossil record that probably experienced periods of extinction such as conifers $[7,8]$, ferns [3,4], gnetophytes [5], and early diverging angiosperm lineages $[107,108]$. One solution might be to replace the commonly used Yule model by the birth-death process, which is more realistic since all clades are likely to have experienced extinction, even young clades currently diversifying.

As a cautionary tale, we suggest that users routinely test between priors to select the prior that best fit their data. Estimators of the marginal likelihood $[82,83]$ are included in BEAST; therefore, model selection can be relatively straightforward. Furthermore, it has been demonstrated that these marginal likelihood estimators accurately compute BF for BRC studies [76], indicating that the results of our empirical study showing the impact of the BPP are reliable.

\section{A late Permian origin for cycads}

According to the dating scenario supported by BF (i.e. timetree reconstructed with six fossil calibrations and a birth-death process), cycads and Ginkgo diverged in the late Carboniferous - early Permian, and the most recent common ancestor of the living cycads is from the late Permian (274.5 Ma). Compared to other dating studies, our timetree fits well with recent works on the genus ages and radiations, but our tree pushes back the origin of cycads more than 50 million years earlier $(\approx 200 \mathrm{Ma}$ for Nagalingum et al. [6]; $\approx 230$ Ma for Salas-Leiva et al. [43]). For the latter, our results are in agreement with other dating studies that used age constraints on the cycad crown $(\approx 280 \mathrm{Ma}$ for Won \& Renner [5]; $\approx 270 \mathrm{Ma}$ for Burleigh et al. [109]). Our cycad timeframe is also 


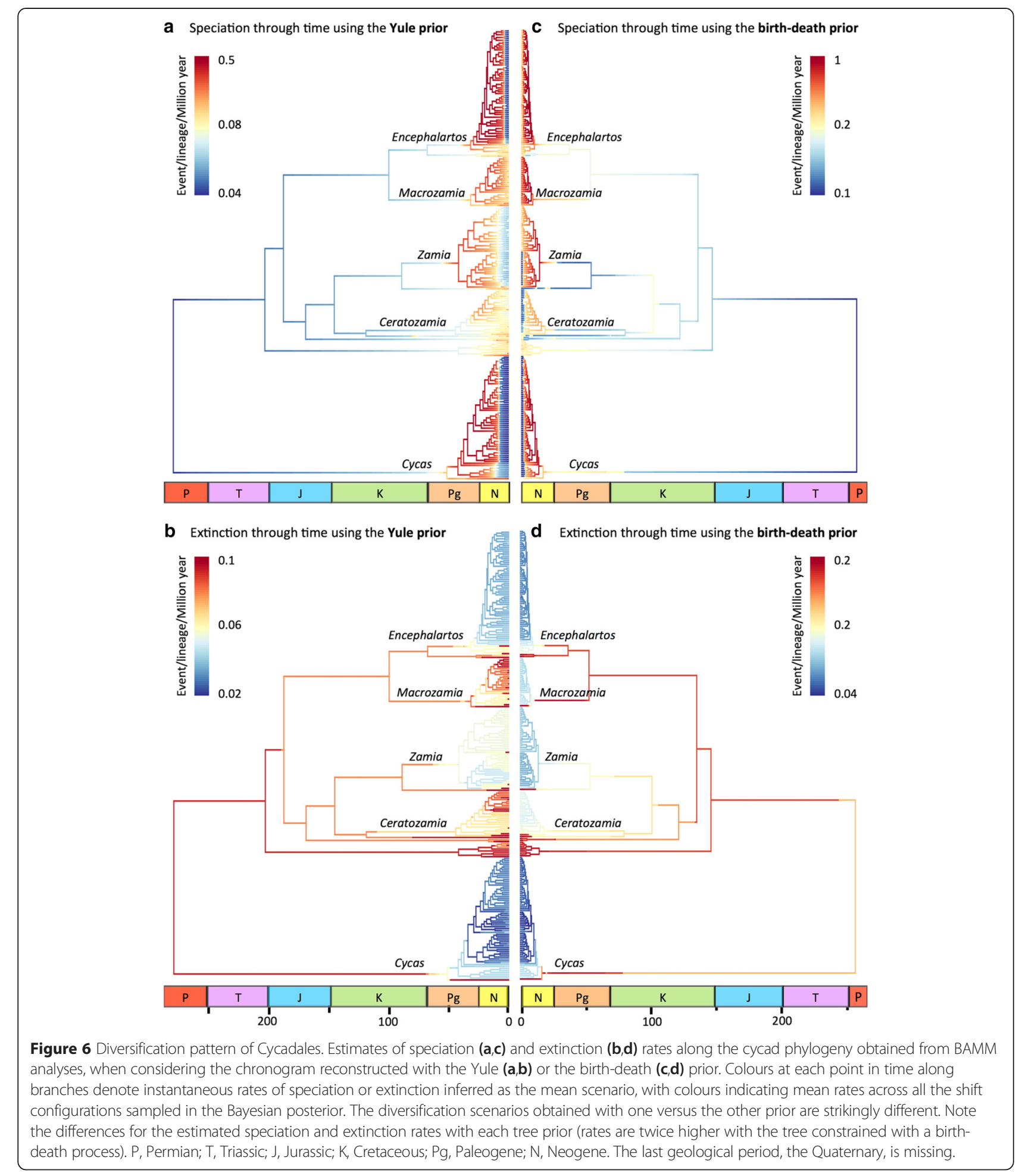

congruent with the cycad insect pollinator of the order Thysanoptera originating and diversifying in the late Permian (286 Ma, [110,111]). Finally our results are in agreement with paleobotanical evidence indicating that cycads first appeared in the late Permian and became more abundant and diverse in the Triassic $[33,39,40]$.
Cycads proliferated during the Mesozoic, an era characterized by an increased occurrence and diversity of fossil cycads, broadly distributed throughout the relatively uniform climate of the supercontinent Pangaea [42]. Notably, the Triassic record of Cycadales is among the most well-known of cycad history, not only because 
of the marked increase in the number of definitive cycad taxa, but also because some of the most well-preserved and informative taxa are from this period [70]. It is generally accepted that cycads first became significant components of terrestrial floras during the Late Triassic as part of a global floral turnover with primitive seed-plant floras being replaced by conifers and cycads after the Permian-Triassic mass extinction (252.2 Ma) $[40,112,113]$. Cycads are generally believed to have reached a diversity peak during the Jurassic, and remained relatively stable in terms of diversity during the Cretaceous [34,112]. Our results further show that major lineages of extant cycads were established during the Early Cretaceous through to the Late Cretaceous, particularly in the Zamiaceae. The current diversity of Zamiaceae stems from surviving lineages of the Cretaceous, a period of rich fossil diversity for the clade $[30,33,114-116]$.

\section{Global diversification pattern of cycads}

The cycad timetree is remarkable for its long branches subtending the genus radiations. The most remarkable example is the branch leading to the genus Cycas that is more than 200 million years long. Our results indicate that extant diversification of cycad species occurred in the Neogene, in agreement with other studies $[6,38,43]$. No crown node of any modern species-rich genus of cycad has an age $>19$ Ma (credibility intervals extend back to 33 and $29 \mathrm{Ma}$ for Ceratozamia and Cycas). Therefore, the ancient stem divergences of genera are decoupled from their recent crown group radiations. This decoupling can be explained by three hypotheses: (i) the long branches represent periods of low diversity, (ii) the long branches may be the result of periods of extinction $[6,38,107,117]$, but it is unknown whether these were few and sudden or highly protracted, or (iii) the presence of ghost lineages, which are lineages that have temporal and/or geographic gaps in their fossil record (e.g. the Cenozoic fossil record of coelacanths). Our results are consistent with the second hypothesis because we show (i) quasi-synchronous and independent shifts in diversification at the crown (or near) of genus radiations that may be interpreted as the recovery period after an extinction event [107,117], and (ii) high rates of extinction along the long branches of the genus stems that may have extirpated entire lineages $[32,33,59]$. Our results, as well as fossil evidence [30-33,39,40,42,114-116], support the role of a mass extinction in shaping the cycad timetree, perhaps in the Late Cretaceous when BAMM extinction rates are elevated.

We found periods of extinction along the long branches of the tree. It is important to mention that these inferred periods of extinction are congruent with fossil data also indicating significant extinctions for the clade. From the Jurassic through the Paleogene, the rate of extinction was high for all lineages. The monotypic genera (Microcycas and Stangeria) and species-poor genera (Bowenia, Dioon, and Lepidozamia) were particularly impacted by extinction (Figure 6). Fossil data and cladistic analyses suggest that, for instance, the lineage today represented by Stangeria might have been more diverse in the past $[32,59,118]$. The surviving cycads re-diversified from the mid- to late Miocene when five lineages, isolated on different continents, underwent successful independent increases in diversification rate. Therefore our results favour the hypothesis of few and sudden extinction events. As potential explanations, this diversification pattern may be attributed to (i) competition with angiosperms (e.g. [34,35,112,113,119]), (ii) changes in, and final extinction of, non-avian dinosaur faunas that may have acted as seed dispersers (for Mesozoic extinction) [41], and/or (iii) global climate change that led to latitudinal shifts of the main vegetation belts and the elimination of cycads from higher latitudes of Eurasia, North America, and Patagonia $[6,110,120]$, perhaps around the EoceneOligocene boundary that marked a significant shift from greenhouse to icehouse climate $[38,121]$.

Discussions on cycad diversity through time are partly hampered due to the difficulty of distinguishing cycad foliage and pollen from that of the extinct (and phylogenetically distinct) clade Bennettitales [39,42]; most previous published diversity curves for Mesozoic plants do not separate Cycadales and Bennettitales, with two clades being grouped together as 'cycadophytes' (e.g. [34,39,112]). Also, the Cretaceous and Cenozoic cycad fossil record is probably too limited to enable understanding of the role of extinction, notably around the Cretaceous-Paleogene boundary. Although their apparent post mid-Cretaceous decline is recognized, we do not have quantitative evidence of the diversity decline nor do we know whether Cenozoic cycad diversity remained low until the Neogene radiations, or whether substantial early to mid-Cenozoic diversity existed but was affected by major extinctions. Besides illustrating the potential effect of BPP choice in Bayesian molecular dating, our study re-examines the dating of the cycads, proving a robust phylogenetic framework for future studies aimed at estimating how the diversity of cycads varied through geological time.

\section{Conclusions}

Our study highlights that the branching process prior (or tree prior) in Bayesian molecular dating has an important effect on age estimates for cycads. The birthdeath process had a better fit than the traditionally used Yule process as determined by marginal likelihood estimates and Bayes factors. It is likely that cycads are not an isolated case and we advocate for a closer investigation of the branching process prior, BPP, in all future molecular phylogenetic dating studies. At minimum we suggest conducting a similar model selection as we did 
for cycads to select the best-fitting prior and thus the best timetree. However, the birth-death process will not necessarily always better fit the data just because it seems more biologically realistic than a simpler Yule model, especially for shallower divergence times (i.e. recent clades). For instance, two recent studies on Australian diving beetles [106] and St. John's wort [122] did not show any age differences using different BPPs, and none of the BPP was supported with Bayes factors; both clades originated in the Oligocene (ca. 34-28 Ma). On the contrary for deeper divergence times, age differences might be revealed when comparing a birth-death and a Yule process as exemplified in a dating study of darkling beetles that originated in the Jurassic ( $\approx 180 \mathrm{Ma})$ [27], but those differences were not as marked as in cycads. Based on these studies and our results, we expect that age differences deriving from different BPPs increase when clade age is very old (e.g. Triassic and backward).

As we gain greater understanding of the priors and parameters associated with molecular dating, there have been accordingly advances in our methodology. We note that other avenues for molecular dating are being developed because the standard dating procedure results in overlaying two prior distributions for a calibration node: one from the tree prior and one from the calibration prior $[19,21,102]$. In the last years, there are new methods that allow the inclusion of fossils in divergence time estimation as noncontemporaneous terminal tips rather than as node calibration points, also known as tip dating [123]. Recently, Heath et al. [103] introduced the fossilized birth-death process, a model for calibrating divergence time estimates in a Bayesian framework, explicitly acknowledging that extant species and fossils are part of the same macroevolutionary process. They argued that a single model that acts as a prior on the speciation times for both calibrated and uncalibrated nodes is a better representation of the lineage diversification process. The approach seems promising and will increasingly be used in future studies, like the application on the royal ferns (family Osmundaceae) [124]. The fossilized birth-death process best fitted the Osmundaceae fossil record and also provided speciation and extinction rates associated with the dated phylogeny.

\section{Availability of supporting data}

The data set supporting the results of this article is available in the Dryad repository, http://dx.doi.org/10.5061/ dryad.20k7m (see ref. [125]).

\section{Additional files}

Additional file 1: Table S1. Taxa sampled and GenBank accession numbers of sequences used in the analyses. All PHYP sequences were generated by Nagalingum et al. [6], and sequences from matK and rbcL were downloaded from GenBank. "-" denotes sequence not available or voucher not indicated.
Additional file 2: Figure S1. Phylogeny of Cycadales reconstructed (for 237 cycad species and three genes) using MrBayes and reversible jump MCMC. Posterior probabilities are shown at nodes. Only the nodes in the backbone are considered well-supported here. Nodes within generic radiations are generally below the standard threshold of robustness. The low node support within genera is likely due to low genetic divergence between species.

Additional file 3: Figure S2. Convergence of the BAMM analysis with the chronogram reconstructed with a Yule prior. (A) The stationary of the MCMC before applying a burn-in. (B) The posterior distribution of number of shifts estimated before applying a burn-in. (C) The stationary of the MCMC after removing the burn-in phase. (D) The posterior distribution of number of shifts estimated after removing the burn-in phase.

Additional file 4: Figure S3. Convergence of the BAMM analysis with the chronogram reconstructed with a birth-death prior. (A) The stationary of the MCMC before applying a burn-in. (B) The posterior distribution of number of shifts estimated before applying a burn-in. (C) The stationary of the MCMC after removing the burn-in phase. (D) The posterior distribution of number of shifts estimated after removing the burn-in phase.

Additional file 5: Figure S4. Frequency distribution of distinct macroevolutionary rate regimes estimated using BAMM and the tree reconstructed with the Yule prior. (A) Prior distribution of the number of distinct processes. (B) Posterior distribution of the number of distinct processes (including the root process) on the cycad phylogeny reconstructed with a Yule model. A one-process model outperforms a two-process model.

Additional file 6: Figure S5. Frequency distribution of distinct macroevolutionary rate regimes estimated using BAMM and the tree reconstructed with the birth-death prior. (A) Prior distribution of the number of distinct processes. (B) Posterior distribution of the number of distinct processes (including the root process) on the cycad phylogeny reconstructed with a birth-death model. A one-process model outperforms a two-process model.

Additional file 7: Figure S6. Credible set of configuration shifts of cycads inferred with BAMM using the (A) tree with the Yule prior, and the $(B)$ tree dated with the birth-death prior. Phylogenies show the distinct shift configurations with the highest posterior probability. For each shift configuration, the locations of rate shifts are shown as red (rate increases) and blue (rate decreases) circles, with circle size proportional to the marginal probability of the shift. Text labels (e.g. $f=0.33$ ) denote the posterior probability of each shift configuration.

Additional file 8: Figure S7. The best shift configuration inferred with BAMM using the (A) tree with the Yule prior, and the (B) tree dated with the birth-death prior. Analysis with the Yule prior indicated a single rate shift (indicated by red circle) near the crowns of Cycas and Encephalartos, whereas the analysis with the birth-death prior indicated four major shifts at the richest genera: Cycas, Zamia, Encephalartos, and Macrozamia.

Additional file 9: Figure S8. Macroevolutionary cohort matrix for speciation of cycads using the birth-death prior. Each cell in the matrix is coded by a color denoting the pairwise probability that two species share a common macroevolutionary rate regime. The cycad phylogeny reconstructed with a birth-death process is shown for reference on the left and upper margins of each cohort matrix. At least five major cohorts can be identified that are the four most species-rich genera: Cycas, Zamia, Encephalartos, and Macrozamia.

Additional file 10: Figure S9. Macroevolutionary cohort matrix for speciation of cycads using the Yule prior. Same legend as Additional file 9: Figure S8.

\section{Abbreviations}

BPP: Branching process prior; BF: Bayes factor; BRC: Bayesian relaxed-clock; ESS: Effective sample size; FC: Fossil calibration; HME: Harmonic mean estimate; HPD: Height posterior density; Ma: Million years ago; MCMC: Markov chain Monte Carlo; MLE: Marginal likelihood estimate; PP: Posterior probability; PSRF: Potential scale reduction factor; SS: Stepping-stone; UCLD: Uncorrelated lognormal distribution clock model. 


\section{Competing interests}

The authors declare that they have no competing interests.

\section{Authors' contributions}

FLC and HM designed the research. FLC retrieved material or data from GenBank, formerly published by NSN and CRM. FLC performed the analyses. FLC wrote the manuscript, with revisions by HM, NSN and CRM. All authors read and approved the final manuscript.

\section{Authors' information}

Fabien Condamine is a post-doc student who is interested in numerous biodiversity patterns such as the latitudinal diversity gradient, regional difference in diversity and island biogeography. He aims to decipher the main evolutionary and ecological processes that have shaped the present pattern of biodiversity. Nathalie Nagalingum is a research scientist who is interested in cycad diversity, its origin, evolution and conservation using genomic and paleontological tools. Charles Marshall is a professor who is interested in how paleontology can inform our understanding of the history of life, and the processes that control it. Hélène Morlon combines mathematics, bioinformatics and fieldwork to study questions ranging from macroevolution and macroecology to community assembly, biogeography, and conservation.

\section{Acknowledgements}

We thank the Associate Editor Rafael Zardoya, and the two referees Susanne Renner and Diego San Mauro who provided insightful comments on the study. We also thank Frédéric Delsuc and Gael Kergoat for discussions, and Simon Ho and Guy Baele for technical comments on the Bayesian analyses. We also thank Daniel Rabosky for the workshop on the BAMM approach, and Mario Coiro for discussions and feedbacks on the fossil record of cycads. Funding was provided by grant ANR CHEX ECOEVOBIO awarded to HM.

\section{Author details}

${ }^{1}$ CNRS, UMR 7641 Centre de Mathématiques Appliquées (École Polytechnique), Route de Saclay, 91128 Palaiseau, France. ${ }^{2}$ Department of Biological and Environmental Sciences, University of Gothenburg, Box 461 , SE-405 30 Göteborg, Sweden. ${ }^{3}$ National Herbarium of New South Wales, Royal Botanic Gardens \& Domain Trust, Mrs Macquaries Road, Sydney, NSW 2000, Australia. ${ }^{4}$ Department of Integrative Biology and Museum of Paleontology, University of California, 1101 Valley Life Sciences Building, Berkeley, CA 94720-4780, USA. ${ }^{5}$ CNRS, UMR 8197 Institut de Biologie de I'École Normale Supérieure, 46 rue d'Ulm, 75005 Paris, France.

\section{Received: 12 January 2015 Accepted: 2 April 2015}

\section{Published online: 17 April 2015}

\section{References}

1. Hedges SB, Kumar S. The Timetree of Life. Oxford: Oxford University Press; 2009

2. Laenen B, Shaw B, Schneider H, Goffinet B, Paradis E, Désamoré A, et al. Extant diversity of bryophytes emerged from successive post-Mesozoic diversification bursts. Nature Comm. 2014;5:5134

3. Schneider H, Schuettpelz E, Pryer KM, Cranfill R, Magallon S, Lupia R. Ferns diversified in the shadow of angiosperms. Nature. 2004;428:553-7.

4. Schuettpelz E, Pryer KM. Evidence for a Cenozoic radiation of ferns in an angiosperm-dominated canopy. Proc Natl Acad Sci U S A. 2009;106:11200-5.

5. Won H, Renner SS. Dating dispersal and radiation in the gymnosperm Gnetum (Gnetales) - Clock calibration when outgroup relationships are uncertain. Syst Biol. 2006;55:610-22.

6. Nagalingum NS, Marshall CR, Quental TB, Rai HS, Little DP, Mathews S. Recent synchronous radiation of a living fossil. Science. 2011;334:796-9.

7. Mao K, Milne Rl, Zhang L, Peng Y, Liu J, Thomas P, et al. Distribution of living Cupressaceae reflects the breakup of Pangea. Proc Natl Acad Sci U S A. 2012;109:7793-8

8. Leslie AB, Beaulieu JM, Rai HS, Crane PR, Donoghue MJ, Mathews S. Hemisphere-scale differences in conifer evolutionary dynamics. Proc Nat Acad Sci U S A. 2012;109:16217-21.

9. Magallón SA, Castillo A. Angiosperm diversification through time. Am J Bot 2009;96:349-65.
10. Fiz-Palacios $\mathrm{O}$, Schneider $\mathrm{H}$, Heinrichs J, Savolainen V. Diversification of land plants: insights from a family-level phylogenetic analysis. BMC Evol Biol. 2011;11:341

11. Zanne AE, Tank DC, Cornwell WK, Eastman JM, Smith SA, FitzJohn RG, et al. Three keys to the radiation of angiosperms into freezing environments. Nature. 2014;506:89-92

12. Percy DM, Page RDM, Cronk QCB. Plant-insect interactions: double-dating associated insect and plant lineages reveals asynchronous radiations. Syst Biol. 2004:53:120-7.

13. Kumar S. Molecular clocks: four decades of evolution. Nature Rev Genet. 2005;6:654-62.

14. Donoghue PCJ, Benton MJ. Rocks and clocks: calibrating the Tree of Life using fossils and molecules. Trends Ecol Evol. 2007;22:424-31.

15. Alfaro ME, Holder MT. The posterior and the prior in Bayesian phylogenetics. Annu Rev Ecol Evol Syst. 2006;37:19-42.

16. Drummond AJ, Ho SYW, Phillips MJ, Rambaut A. Relaxed phylogenetics and dating with confidence. PLoS Biol. 2006;4:e88.

17. Inoue J, Donoghue PCJ, Yang Z. The impact of the representation of fossil calibrations on Bayesian estimation of species divergence times. Syst Biol. 2010:59:74-89.

18. Yang Z, Rannala B. Bayesian estimation of species divergence times under a molecular clock using fossil calibrations with soft bounds. Mol Biol Evol. 2006;23:212-26.

19. Ho SYW, Phillips MJ. Accounting for calibration uncertainty in phylogenetic estimation of evolutionary divergence times. Syst Biol. 2009:58:367-80.

20. Yang Z, Rannala B. Branch-length prior influences Bayesian posterior probability of phylogeny. Syst Biol. 2005;54:455-70.

21. Heled J, Drummond AJ. Calibrated birth-death phylogenetic time-tree priors for Bayesian inference. Syst Biol. 2015;64:369-383.

22. Morlon H. Phylogenetic approaches for studying diversification. Ecol Lett. 2014;17:508-25.

23. Yang Z, Goldman N, Friday A. Maximum likelihood tree from DNA sequences: a peculiar statistical estimation problem. Syst Biol. 1995;44:384-99.

24. Rannala B, Yang Z. Probability distribution of molecular evolutionary trees: a new method of phylogenetic inference. J Mol Evol. 1996;43:304-11.

25. Gernhard T. The conditioned reconstructed process. J Theoret Biol. 2008;253:769-78.

26. Drummond AJ, Suchard MA, Xie D, Rambaut A. Bayesian phylogenetics with BEAUti and the BEAST 1.7. Mol Biol Evol. 2012;29:1969-73.

27. Kergoat GJ, Bouchard P, Clamens A-L, Abbate $J$, Jourdan $H$, Zahab R, et al. Cretaceous environmental changes led to high turnovers and decreases in diversification rates in a hyperdiverse non-phytophagous beetle family. BMC Evol Biol. 2014;14:220.

28. Couvreur TLP, Franzke A, Al-Shehbaz IA, Bakker F, Koch M, Mummenhoff K. Molecular phylogenetics, temporal diversification and principles of evolution in the mustard family (Brassicaceae). Mol Biol Evol. 2010;27:55-71.

29. Osborne R, Calonje MA, Hill KD, Stanberg L, Stevenson DW. The world list of Cycads. Mem New York Botl Gard. 2012;106:480-510.

30. Pant DD. The fossil history and phylogeny of the cycadales. Geophytol. 1987:17:125-62.

31. Axsmith BJ, Serbet R, Krings M, Taylor TN, Taylor EL, Mamay SH. The enigmatic Paleozoic plants Spermopteris and Phasmatocycas reconsidered. Am J Bot. 2003;90:1585-95.

32. Hermsen EJ, Taylor TN, Taylor EL, Stevenson DW. Cataphylls of the Middle Triassic cycad Antarcticycas schopfii and new insights into cycad evolution. Am J Bot. 2006;93:724-38.

33. Cúneo NR, Escapa I, Villar-de-Seoane L, Artabe A, Gnaedinger S. Review of the Cycads and Bennettitaleans from the Mesozoic of Argentina. In: Gee CT, editor. Plants in Mesozoic Time: Morphological Innovations, Phylogeny, Ecosystems. Bloomington: Indiana University Press; 2010. p. 187-212.

34. Crane PR. Vegetational consequences of the angiosperm diversification. In: Friis EM, Chaloner WC, Crane PR, editors. The Origin of Angiosperms and their Biological Consequences. Cambridge: Cambridge University Press; 1987. p. 107-44.

35. Lupia R, Lidgard S, Crane PR. Comparing palynological abundance and diversity: implications for biotic replacement during the Cretaceous angiosperm radiation. Paleobiol. 1999;25:305-40.

36. van de Schootbrugge B, Quan TM, Lindström S, Püttmann W, Heunisch C, Pross J, et al. Floral changes across the Triassic/Jurassic boundary linked to flood basalt volcanism. Nature Geosci. 2009;2:589-94. 
37. Coiffard C, Gomez B, Daviero-Gomez V, Dilcher DL. Rise to dominance of angiosperm pioneers in European Cretaceous environments. Proc Natl Acad Sci U S A. 2012;109:20955-9.

38. Crisp MD, Cook LG. Cenozoic extinctions account for the low diversity of extant gymnosperms compared with angiosperms. New Phytol. 2011;192:997-1009.

39. Willis K, McElwain JC. The Evolution of Plants. Oxford: Oxford University Press; 2002.

40. McElwain JC, Punyasena SW. Mass extinction events and the fossil record. Trends Ecol Evol. 2007;22:548-57.

41. Butler RJ, Barrett PM, Kenrick P, Penn MG. Testing co-evolutionary hypotheses over geological timescales: interactions between Mesozoic nonavian dinosaurs and cycads. Biological Rev. 2009;84:73-89.

42. Taylor TN, Taylor EL, Krings M. Paleobotany: The Biology and Evolution of Fossil Plants. 2nd ed. Burlington: Academic Press; 2009.

43. Salas-Leiva DE, Meerow AW, Calonje M, Griffith MP, Francisco-Ortega J, Nakamura K, et al. Phylogeny of the cycads based on multiple single-copy nuclear genes: congruence of concatenated parsimony, likelihood and species tree inference methods. Ann Bot. 2013;112:1263-78.

44. Hollick A. Descriptions of new species of Tertiary cycads, with a review of those previously recorded. Bull Torrey Bot Club. 1932;59:169-89.

45. Hill RS. Three new Eocene cycads from eastern Australia. Austral J Bot. 1980;28:105-22.

46. Horiuchi J, Kimura T. Dioonopsis nipponica gen et sp. nov, a new cycad from the Palaeogene of Japan. Rev Palaeobot Palynol. 1987;51:213-25.

47. Kvaček Z. A new Tertiary Ceratozamia (Zamiaceae, Cycadopsida) from the European Oligocene. Flora - Morphology, Distribution Functional Ecology of Plants. 2002;197:303-16.

48. Erdei B, Manchester SR, Kvaček Z. Dioonopsis Horiuchi et Kimura leaves from the Eocene of Western North America: a cycad shared with the Paleogene of Japan. Intl J Plant Sci. 2012;173:81-95.

49. Kvaček Z. New fossil records of Ceratozamia (Zamiaceae, Cycadales) from the European Oligocene and lower Miocene. Acta Palaeobot. 2014;54:231-47.

50. Su K, Quan C, Liu Y-S. Cycas fushunensis sp. nov. (Cycadaceae) from the Eocene of northeast China. Rev Palaeobot Palynol. 2014;204:43-9.

51. Griffith MP, Magellan TM, Tomlinson PB. Variation in leaflet structure in Cycas (Cycadales: Cycadaceae): Does anatomy follow phylogeny and geography? Intl J Plant Sci. 2014;175:241-55.

52. González D, Vovides AP. Low intralineage divergence in Ceratozamia (Zamiaceae) detected with nuclear ribosomal DNA ITS and chloroplast DNA trnL-F non-coding region. Syst Bot. 2002;27:654-61.

53. Hill KD, Chase MW, Stevenson DW, Hill HG, Schutzman B. The families and genera of cycads: a molecular phylogenetic analysis of Cycadophyta based on nuclear and plastid DNA sequences. Intl J Plant Sci. 2003;164:933-48.

54. Rai HS, O'Brien HE, Reeves PA, Olmstead RG, Graham SW. Inference of higher-order relationships in the cycads from a large chloroplast data set. Mol Phylogenet Evol. 2003;29:350-9.

55. Chaw S-M, Walters TW, Chang C-C, Hu S-H, Chen S-H. A phylogeny of cycads (Cycadales) inferred from chloroplast matK gene, trnK intron, and nuclear rDNA ITS region. Mol Phylogenet Evol. 2005;37:214-34.

56. González D, Vovides AP, Barcenas C. Phylogenetic relationships of the Neotropical genus Dioon (Cycadales, Zamiaceae) based on nuclear and chloroplast DNA sequence data. Syst Bot. 2008:33:229-36.

57. Yessoufou K, Bamigboye SO, Daru BH, van der Bank M. Evidence of constant diversification punctuated by a mass extinction in the African cycads. Ecol Evol. 2013:4:50-8.

58. Wu CH, Chaw SM, Huang YY. Chloroplast phylogenomics indicates that Ginkgo biloba is sister to cycads. Genome Biol Evol. 2013:5:243-54.

59. Martínez LCA, Artabe AEE, Bodnar J. A new cycad stem from the Cretaceous in Argentina and its phylogenetic relationships with other Cycadales. Bot J Linn Soc. 2012;170:436-58.

60. Sauquet H, Ho SYW, Gandolfo MA, Jordan GJ, Wilf P, Cantrill DJ, et al. Testing the impact of calibration on molecular divergence times using a fossilrich group: the case of Nothofagus (Fagales). Syst Biol. 2012;61:289-313.

61. Near TJ, Meylan PA, Shaffer HB. Assessing concordance of fossil calibration points in molecular clock studies: an example using turtles. Am Nat. 2005;165:137-46.

62. Clarke JT, Warnock RCM, Donoghue PCJ. Establishing a time-scale for plant evolution. New Phytol. 2011;192:266-301.

63. Gradstein FM, Ogg JG, Schmitz MD, Ogg GM. The Geologic Time Scale 2012, Volume Set. Boston, USA: Elsevier; 2012.
64. Zhu JN, Zhang SS, Ma J. A new genus and species - Cycadostrobus paleozoicus Zhu of Cycadaceae from the Permian of China. Acta Phytotaxo Sinica. 1994;32:340-4.

65. Zhu JN, Du XM. A new cycad - Primocycas chinensis gen. et sp. nov. discovers from the Lower Permian in Sha-nxi, China and its significance. Acta Bot Sinica. 1981;23:401-4.

66. Zhifeng $G$, Thomas BA. A review of fossil cycad megasporophylls, with new evidence of Crossozamia Pomel and its associated leaves from the Lower Permian of Taiyuan, China. Rev Palaeobot Palynol. 1989;60:205-23.

67. Wang J. Late Paleozoic macrofloral assemblages from Weibei Coalfield, with reference to vegetational change through the Late Paleozoic Ice-age in the North China Block. Intl J Coal Geol. 2010;83:292-317.

68. Hill RS. Two new species of Bowenia Hook, ex Hook, f. from the Eocene of eastern Australia. Austral J Bot. 1978;26:837-46.

69. Smoot EL, Taylor TN, Delevoryas T. Structurally preserved fossil plants from Antarctica. I. Antarcticycas, gen. nov., a Triassic cycad stem from the Beardmore Glacier area. Am J Bot. 1985:72:1410-23.

70. Hermsen EJ, Taylor EL, Taylor TN. Morphology and ecology of the Antarcticycas plant. Rev Palaeobot Palynol. 2009;153:108-23.

71. Rothwell GW, Scheckler SE, Gillespie WH. Elkinsia gen nov, a Late Devonian gymnospermn with cupulate ovules. Bot Gazette. 1989:150:170-89.

72. Ronquist F, Teslenko M, Van der Mark P, Ayres DL, Darling A, Höhna S, et al. MrBayes 3.2: efficient Bayesian phylogenetic inference and model choice across a large model space. Syst Biol. 2012;61:539-42.

73. Lanfear R, Calcott B, Ho SYW, Guindon S. PartitionFinder: combined selection of partitioning schemes and substitution models for phylogenetic analyses. Mol Biol Evol. 2012;29:1695-701.

74. Huelsenbeck JP, Larget B, Alfaro ME. Bayesian phylogenetic model selection using reversible jump Markov chain Monte Carlo. Mol Biol Evol. 2004:21:1123-33.

75. Rambaut A, Suchard MA, Xie D, Drummond AJ. Tracer v1.6. Available at: http://beast.bio.ed.ac.uk/Tracer; 2015

76. Baele G, Li WLS, Drummond AJ, Suchard MA, Lemey P. Accurate model selection of relaxed molecular clocks in Bayesian phylogenetics. Mol Biol Evol. 2013;30:239-43.

77. Vanneste K, Baele G, Maere S, Van de Peer Y. Analysis of 41 plant genomes supports a wave of successful genome duplications in association with the Cretaceous-Paleogene boundary. Genome Res. 2014;24:1334-47.

78. Warnock RCM, Parham JF, Joyce WG, Lyson TR, Donoghue PCJ. Calibration uncertainty in molecular dating analyses: there is no substitute for the prior evaluation of time priors. Proc R Soc B. 2015:282:20141013.

79. Near TJ, Sanderson MJ. Assessing the quality of molecular divergence time estimates by fossil calibrations and fossil-based model selection. Philos T R Soc B. 2004;359:1477-83

80. Ayres DL, Darling A, Zwickl DJ, Beerli P, Holder MT, Lewis PO, et al. BEAGLE: an application programming interface and high-performance computing library for statistical phylogenetics. Syst Biol. 2012;61:170-3.

81. Miller MA, Schwartz T, Pickett BE, He S, Klem EB, Scheuermann RH, et al. A RESTful API for Access to Phylogenetic Tools via the CIPRES Science Gateway. Evol Bioinformatics. 2015;11:43-8.

82. Lartillot N, Philippe H. Computing Bayes factors using thermodynamic integration. Syst Biol. 2006;55:195-207.

83. Xie W, Lewis PO, Fan Y, Kuo L, Chen MH. Improving marginal likelihood estimation for Bayesian phylogenetic model selection. Syst Biol. 2011;60:150-60.

84. Kass RE, Raftery AE. Bayes factors. J Am Stat Assoc. 1995;90:773-95.

85. Rabosky DL, Santini F, Eastman JM, Smith SA, Sidlauskas B, Chang J, et al. Rates of speciation and morphological evolution are correlated across the largest vertebrate radiation. Nature Comm. 2013:4:1958.

86. Rabosky DL, Donnellan SC, Grundler M, Lovette IJ. Analysis and visualization of complex macroevolutionary dynamics: an example from Australian scincid lizards. Syst Biol. 2014;63:610-27.

87. Rabosky DL. Automatic detection of key innovations, rate shifts, and diversity dependence on phylogenetic trees. PLoS One. 2014;9:e89543.

88. Paradis E. Can extinction rates be estimated without fossils? J Theor Biol. 2004;229:19-30

89. Quental TB, Marshall CR. Diversity dynamics: molecular phylogenies need the fossil record. Trends Ecol Evol. 2010;25:434-41.

90. Rabosky DL. Extinction rates should not be estimated from molecular phylogenies. Evolution. 2010;64:1816-24.

91. Nee S, Holmes EC, May RM, Harvey PH. Extinction rates can be estimated from molecular phylogenies. Philos Trans R Soc B. 1994;344:77-82. 
92. Purvis A. Phylogenetic approaches to the study of extinction. Annu Rev Ecol Evol Syst. 2008;39:301-19.

93. Morlon H, Parsons TL, Plotkin JB. Reconciling molecular phylogenies with the fossil record. Proc Natl Acad Sci U S A. 2011;108:16327-32.

94. Beaulieu JM, O'Meara BC. Extinction can be estimated from moderately sized molecular phylogenies. Evolution. 2015, doi.org/10.1111/evo.12614

95. Huang S, Chiang YC, Schaal BA, Chou CH, Chiang TY. Organelle DNA phylogeography of Cycas taitungensis, a relict species in Taiwan. Mol Ecol. 2001;10:2669-81.

96. Xiao LQ, Möller M. Nuclear ribosomal its functional paralogs resolve the phylogenetic relationships of a late-Miocene radiation cycad Cycas (Cycadaceae). PLoS One. 2015;10:e0117971.

97. Treutlein J, Vorster P, Wink M. Molecular relationships in Encephalartos (Zamiaceae, Cycadales) based on nucleotide sequences of nuclear ITS 1\&2, rbcL, and genomic ISSR fingerprinting. Plant Biol. 2005;7:79-90.

98. Sharma IK, Jones DL, Forster PI. Genetic differentiation and phenetic relatedness among seven species of the Macrozamia plurinervia complex (Zamiaceae). Biochem Syst Ecol. 2004;32:313-27.

99. Caputo P, Cozzolino S, Gaudio L, Moretti A, Stevenson D. Karyology and phylogeny of some mesoamerican species of Zamia (Zamiaceae). Am J Bot. 1996:83:1513-20.

100. Zgurski JM, Rai HS, Fai QM, Bogler DJ, Francisco-Ortega J, Graham SW. How well do we understand the overall backbone of cycad phylogeny? New insights from a large, multigene plastid data set. Mol Phylogenet Evol. 2008;47:1232-7.

101. Raup DM. Extinction: Bad genes or bad luck? New York: W.W. Norton and Company; 1991

102. Heled J, Drummond AJ. Calibrated tree priors for relaxed phylogenetics and divergence time estimation. Syst Biol. 2012;61:138-49.

103. Heath TA, Huelsenbeck JP, Stadler T. The fossilized birth-death process for coherent calibration of divergence-time estimates. Proc Natl Acad Sci U S A. 2014;111:E2957-66.

104. Hagen O, Hartmann K, Steel M, Stadler T. Age-dependent speciation can explain the shape of empirical phylogenies. Syst Biol. 2015;64:432-440.

105. Drummond AJ, Bouckaert RR. Bayesian evolutionary analysis with BEAST. Cambridge: Cambridge University Press; 2015.

106. Toussaint EFA, Condamine FL, Hawlitschek O, Watts CHS, Porch N, Hendrich $L$, et al. Unveiling the diversification dynamics of Australasian predaceous diving beetles in the Cenozoic. Syst Biol. 2015;64:3-24.

107. Antonelli A, Sanmartín I. Mass extinction, gradual cooling, or rapid radiation? Reconstructing the spatiotemporal evolution of the ancient angiosperm genus Hedyosmum (Chloranthaceae) using empirical and simulated approaches. Syst Biol. 2011;60:596-615.

108. Thomas N, Bruhl JJ, Ford A, Weston PH. Molecular dating of Winteraceae reveals a complex biogeographical history involving both ancient Gondwanan vicariance and long-distance dispersal. J Biogeogr. 2014;41:894-904.

109. Burleigh JG, Brabazuk WD, Davis JM, Morse AM, Soltis PS. Exploring diversification and genome size evolution in extant gymnosperms through phylogenetic synthesis. J Bot. 2012;2012:1-6.

110. Peñalver E, Labandeira CC, Barrón E, Delclòs X, Nel P, Nel A, et al. Thrips pollination of Mesozoic gymnosperms. Proc Natl Acad Sci U S A. 2012;109:8623-8.

111. Rainford JL, Hofreiter M, Nicholson DB, Mayhew PJ. Phylogenetic distribution of extant richness suggests metamorphosis is a key innovation driving diversification in insects. PLoS One. 2014;9:e109085.

112. Niklas KJ, Tiffney BH, Knoll AH. Patterns in vascular land plant diversification. Nature. 1983;303:614-6.

113. Silvestro D, Cascales-Miñana B, Bacon CD, Antonelli A. Revisiting the origin and diversification of vascular plants through a comprehensive Bayesian analysis of the fossil record. New Phytol. in press, doi.org/10.1111/nph.13247.

114. Artabe A, Archangelsky S. Las Cycadales Mesodescolea plicata Archangelsky emend. Archangelsky y Petriella 1971 (Cretacio) y Stangeria Moore (Actual). Estudio comparativo de epidermis foliar con microscopia electr6nica de barrido y transmisi6n. Ameghiniana. 1992;28:115-23.

115. Artabe A, Stevenson DW. Fossil Cycadales of Argentina. Botanical Rev. 1999;65:219-38

116. Passalia MG, Del Fueyo G, Archangelsky S. An Early Cretaceous zamiaceous cycad of South West Gondwana: Restrepophyllum nov. gen. from Patagonia, Argentina. Rev Palaeobot Palynol. 2010;161:137-50.

117. Crisp MD, Cook LG. Explosive radiation or cryptic mass extinction? Interpreting signatures in molecular phylogenies. Evolution. 2009;63:2257-65.
118. Uzunova K, Palamarev E, Kvaček Z. Eostangeria ruzinciniana (Zamiaceae) from the Middle Miocene of Bulgaria and its relationship to similar taxa of fossil Eostangeria, and extant Chigua and Stangeria (Cycadales). Acta Palaeobot. 2001:41:177-93.

119. Nagalingum NS, Drinnan AN, Lupia R, McLoughlin S. Fern spore diversity and abundance in Australia during the Cretaceous. Rev Palaeobot Palynol. 2002;119:69-92.

120. Tang W. The evolutionary history of North American cycads. Cycad Newslett. 2012;35:7-13.

121. Cramer BS, Miller KG, Barrett PJ, Wright JD. Late Cretaceous-Neogene trends in deep ocean temperature and continental ice volume: Reconciling records of benthic foraminiferal geochemistry $\left(\delta^{18} \mathrm{O}\right.$ and $\left.\mathrm{Mg} / \mathrm{Ca}\right)$ with sea level history. J Geophys Res: Oceans. 2011;116:1978-2012.

122. Meseguer AS, Lobo JM, Ree R, Beerling DJ, Sanmartín I. Integrating fossils, phylogenies, and niche models into biogeography to reveal ancient evolutionary history: the case of Hypericum (Hypericaceae). Syst Biol. 2015;64:215-32.

123. Ronquist F, Klopfstein S, Vilhelmsen L, Schulmeister S, Murray DL, Rasnitsyn AP. A total-evidence approach to dating with fossils, applied to the early radiation of the Hymenoptera. Syst Biol. 2012;61:973-99.

124. Grimm GW, Kapli P, Bomfleur B, McLoughlin S, Renner SS. Using more than the oldest fossils: Dating Osmundaceae with three Bayesian clock approaches. Syst Biol. 2015;64:96-405.

125. Condamine FL, Nagalingum NS, Marshall CR, Morlon H. Data from: Origin and diversification of living cycads: A cautionary tale on the impact of the branching process prior in Bayesian molecular dating. BMC Evol Biol. 2015, http://dx.doi.org/10.5061/dryad.20k7m

\section{Submit your next manuscript to BioMed Central and take full advantage of:}

- Convenient online submission

- Thorough peer review

- No space constraints or color figure charges

- Immediate publication on acceptance

- Inclusion in PubMed, CAS, Scopus and Google Scholar

- Research which is freely available for redistribution 